\title{
Divergent DNA methylation signatures of juvenile seedlings grafts and adult apple trees
}

Adrien Perrin ${ }^{1}$, Nicolas Daccord ${ }^{1}$, David Roquis ${ }^{1,2}$, Jean-Marc Celton ${ }^{1}$, Emilie Vergne ${ }^{1}$ and Etienne Bucher ${ }^{1,2}$

${ }^{1}$ IRHS (Institut de Recherche en Horticulture et Semences), UMR 1345, INRA, AgrocampusOuest, Université d'Angers, SFR 4207 QuaSaV, Beaucouzé F-49071, France

${ }^{2}$ Plant Breeding and Genetic Resources, Agroscope, Nyon, Switzerland Correspondence: etienne.bucher@agroscope.admin.ch

Summary sentence: In apple the partial transmission of DNA methylation marks indicates

Author contributions: E.B. and JM.C. conceived original research plan; A.P., JM.C. and E.V. performed research; A.P., N.D., D.R., JM.C, E.V., and E.B. analyzed data; A.P., JM.C., E.V. and E.B. wrote the paper; and JM.C. and E.B. agrees to serve as the author responsible for contact and ensures communications.

Funding information: This research was funded by the EPICENTER ConnecTalent grant of the Pays de la Loire (E.B.).

\begin{abstract}
:
Plants are continuously exposed to environmental perturbations. Outcrossing annual plants can adapt rapidly to these changes via sexual mating and DNA mutations. However, perennial and clonally reproducing plants may have developed particular mechanisms allowing them to adapt to these changes and transmit this information to their offspring. It has been proposed that the mechanisms allowing this plasticity of response could come in the form of epigenetic marks that would evolve throughout a plant's lifetime and modulate gene expression. To study these mechanisms, we used apple (Malus domestica) as a model perennial and clonally propagated plant. First, we investigated the DNA methylation patterns of mature trees compared to juvenile seedlings. While we did not observe a drastic genomewide change in DNA methylation levels, we found clear changes in DNA methylation patterns localized in regions enriched in genes involved in photosynthesis. Transcriptomic analysis showed that genes involved in this pathway were overexpressed in seedlings. Secondly, we compared global DNA methylation of a newly grafted plant to its mother tree to assess if acquired epigenomic marks were transmitted via grafting. We identified clear changes, albeit showing weaker DNA methylation differences. Our results show that a majority of DNA methylation patterns from the tree are transmitted to newly grafted plants albeit with specific local differences. Both the epigenomic and transcriptomic data indicate that grafted plants are at an intermediate phase between an adult tree and seedling and inherit part of the epigenomic history of their mother tree.
\end{abstract}


bioRxiv preprint doi: https://doi.org/10.1101/818690; this version posted October 25, 2019. The copyright holder for this preprint (which was not certified by peer review) is the author/funder, who has granted bioRxiv a license to display the preprint in perpetuity. It is made available under aCC-BY-NC 4.0 International license.

43 Key words: epigenetics, perennial plant, heritability, Malus domestica, sexual and asexual 44 reproduction 


\section{Introduction}

Epigenetic regulation of gene transcription is implemented by several covalent modifications occurring at the histone or DNA level without affecting the DNA sequence itself (Holliday and Pugh 1975). These modifications are termed epigenetic marks and can change throughout plant development. Some newly acquired epigenetic changes can also be inherited across generations (Hauser et al. 2011; Gutierrez-Marcos and Dickinson 2012; Kawashima and Berger 2014; Quadrana and Colot 2016). During their lifetime organisms may develop alternative phenotypes in response biotic and abiotic stresses (Madlung and Comai 2004; Mirouze and Paszkowski 2011; Köhler, Wolff, and Spillane 2012; Song, Irwin, and Dean 2013). These stimuli result in modifications in gene transcription which can be altered by epigenetic modifications (Manning et al. 2006; Schmitz et al. 2013; Kim and Zilberman 2014). Besides gene transcription changes, certain epigenetic marks have been shown to play key roles in DNA conformation and genome stability (Suzuki and Bird 2008; Hauser et al. 2011; Kim and Zilberman 2014). Indeed, DNA methylation has been shown to have a major role in transposable element (TE) silencing by reducing considerably the potential damage incurred by de novo TE insertions in the genome (Miura et al. 2001; Mirouze et al. 2009; Ito et al. 2011).

At the molecular level, DNA methylation consists in the covalent addition of a methyl group to cytosine nucleotide. In plants, DNA methylation occurs in three different cytosine contexts: CG, CHG and CHH (H= A, T or C) (Gruenbaum et al. 1981; Meyer, Niedenhof, and Ten Lohuis 1994; Finnegan et al. 1998; Chan, Henderson, and Jacobsen 2005). DNA methylation is established de novo or maintained by several DNA methyltransferase enzymes (Law and Jacobsen 2010), each having a specific role depending on the sequence context. In order to maintain DNA methylation following DNA replication that results in hemi-methylated DNA, the methyltransferases MET1 and CMT3 can copy DNA methylation patterns from the "ancestral" strand to the newly synthesized strand. This mechanism is called DNA methylation maintenance (Lindroth 2001; Schermelleh et al. 2007) and occurs at symmetric CG and CHG sequence contexts. However, for the $\mathrm{CHH}$ sequence context is no such template exists that may allow the DNA methylation maintenance mechanism. In this case, DNA methylation has to be restored by de novo methylation after each DNA replication cycle (Wassenegger et al. 1994; Chedin, Lieber, and Hsieh 2002). This pathway is called RNAdirected DNA methylation (RdDM) and requires small interfering RNAs (siRNA) (Herr et al. 2005; Kanno et al. 2005) to guide the DNA methylation machinery regions with sequence homology to the siRNAs.

From an epigenetic point of view, perennial plants are of particular interest as they have the potential to accumulate epigenetic modifications throughout their lifetime and may pass this information to the next generation. In addition, in the Rosacea family (Jung et al. 2019) numerous crops and ornamental plants are multiplied by asexual multiplication via grafting. This is interesting because in addition to the long lifetime of these plants, asexual multiplication involves only mitotic cell divisions (Verhoeven and Preite 2014) and thus presumably increases the chances of transmission of acquired epigenetic marks. If that was the case, epimutations could be quite common in grafted perennial plants. In contrast, during sexual reproduction meiosis can result in epigenetic reprogramming and therefore the loss of acquired epigenetic marks (Choi et al. 2002; Ibarra et al. 2012; Li, Kumar, and Qian 2018). In Arabidopsis, this reprogramming is the result of active DNA demethylation 
driven by DEMETER (DME) (Choi et al. 2002). Previous studies have suggested that this demethylation could contribute to the generation of totipotent cells (Slotkin et al. 2009; Gutierrez-Marcos and Dickinson 2012; Kawashima and Berger 2014) by alleviating gene silencing via active removal of DNA methylation. These modifications at the DNA methylation level are necessary for normal meiosis (Walker et al. 2018). The RdDM pathway remains active in the egg cell (Olmedo-Monfil et al. 2010). However, in the central cell of the mature female gametophyte and in the mature pollen sperm cell there is a decrease in RdDM activity (Kawashima and Berger 2014). This decrease releases the transcription of TEs, thus resulting in the production of siRNAs derived from those. These siRNAs have been reported to be transported into the egg cell (Han et al. 2000) to silence homologous loci in the maternal and paternal genomes (Han et al. 2000; Saze, Scheid, and Paszkowski 2003; Jablonka and Raz 2009; Feng, Jacobsen, and Reik 2010; Kawashima and Berger 2014). Based on these findings, one may assume that during sexual multiplication, meiosis would allow restauration of a specific DNA methylation level in these species, while during asexual multiplication mitosis would maintain epimutations.

In plants, inheritance of epigenetic marks has been widely investigated. Some studies point out the existence of broad epigenetic variations throughout wild populations of perennial and annual plants (Herrera, Medrano, and Bazaga 2016; Niederhuth et al. 2016; Wilschut et al. 2016). Other studies have demonstrated that epigenomic plasticity can allow environmental stress adaptation and improve response to future stresses (Herman and Sultan 2011; Herrera and Bazaga 2013; Medrano, Herrera, and Bazaga 2014; Colicchio et al. 2015). Finally, studies have suggested that epigenetic modifications induced by stress in a mother plant may improve stress response in their offspring (Agrawal, Strauss, and Stout 1999; Bilichak and Kovalchuk 2016; Ramírez-Carrasco, Martínez-Aguilar, and AlvarezVenegas 2017). However, still little is known about heritable transmission of epigenetic marks in crops and more specifically in woody perennials like apple.

Apple (Malus domestica) is a major fruit crop in the world. In 2017, 130 million tons of fruit were produced on 12,3 million hectares ("FAOSTAT" 2017). In the Malus gender, tree multiplication for commercial orchards and conservation is performed via asexual multiplication. This vegetative multiplication (or clonal multiplication) obtained by grafting or budding ensures that all grafted trees originating from a particular cultivar are genetically similar. Scions of fruiting cultivars are grafted on rootstock to combine valuable agricultural traits. For instance, in addition to reducing tree size and modifying its architecture, grafting onto particular rootstocks is known to shorten the juvenile phase of the scion by promoting flower differentiation (Lane 1992). Scions can thus recover their ability to bloom 3 to 5 years after grafting (Lane 1992) while seedlings on their own roots may only start blooming after up to 8 years (Visser 1964). The juvenile phase is the first stage of development of new plants derived from sexual reproduction (Lavee et al. 1996). Juvenile phase length is highly variable among species, ranging from a few days, as in the Rosa genus (Hackett and Murray 2015) to more than 30 years in some woody plants (Rugini 1986; Bellini 1993; Meilan 1997). Certain phenotypic characteristics have been associated with the juvenile phase such as fast vegetative growth (Meilan 1997), low lignification of young shoots, short internodes, specific leaf shape (Lavee et al. 1996) and low trichome density. For instance, this phenotypic difference between juveniles and adults has previously been described in annual plants such as Arabidopsis (Telfer, Bollman, and Poethig 1997) or Zea mays (Poethig 2003), and 
139 perennials including the Acacia genus, Eucalyptus globulus, Hedera helix, Quercus acutissima 140 (Wang et al. 2011) or in Populus trichocarpa (Critchfield 1960).

Here we investigated the transmission of epigenetic marks at the DNA methylation 143 level using a recently completely sequenced apple doubled-haploid Golden Delicious line 144 (GDDH13) (Lespinasse et al. 1999; Daccord et al. 2017). Taking advantage of this unique genetic material, we compared the effect of sexual and asexual multiplication at the phenotypic, gene transcription and DNA methylation levels. We present evidence that genome-wide DNA methylation levels are stable in apple independently of its multiplication mode. However, specific local variations in DNA methylation patterns involved in the regulation of key plant-specific gene regulatory networks such as photosynthesis were found and provide the basis for future studies on the role of epigenetics in tree aging. 


\section{Results}

152

153

154

155

156

157

158

159

160

161

162

163

164

165

166

167

168

169

170

171

172

173

174

175

176

177

178

179

180

181

182

183

184

185

186

187

188

189

190

191

192

193

194

195

196

197

\section{Phenotypic comparison of seedlings, young grafts and adult trees}

We found that the GDDH13 doubled haploid apple showed a relatively high selfcompatibility level as compared to the original 'Golden Delicious' variety from which it was derived. To prevent outcrossing and to produce self-fertilized GDDH13 seeds we covered trees with insect- and wind-proof cages during blooming time. Then we deployed bumblebees in the cages resulting in the production of hundreds of self-fertilized seeds. This unique material allowed us to study genetically identical seedlings and grafted plantlets derived from the very same parental tree. For that purpose, we simultaneously planted seedlings and grafted budwood from GDDH13 to ensure that the growing plants were of comparable size.

First, we studied the phenotypic differences between parental tree, grafts and seedlings on leaf samples in order to assess if the plants were in a juvenile or adult phase. Trichome density was the most noticeable phenotypic difference (Fig. 1). Leaves sampled from seedlings (Seedling) displayed a notably lower trichome density on their abaxial face (Fig. 1A) compared to the other samples. Leaves sampled from grafted plants (Graft) or from the original parental tree (Tree) showed a significantly higher trichome density (Fig. 1B-D).

In order to describe the gene regulatory mechanisms that may be underlying the observed phenotypic differences, we carried out transcriptomic analyses.

\section{Transcriptional profiles of seedlings, young grafts and adult trees}

In order to identify genes related to the juvenile phenotype or genes displaying differential transcription levels in response to grafting, we performed a set of differential gene transcription analyses. We assessed steady state RNA levels by performing the following two comparisons: Tree versus Seedling (TVS) and Tree versus Graft (TvG). Transcriptomes were obtained using a custom-designed microarray that includes probes from all annotated GDDH13 genes and a fraction of TEs. We identified 6.943 and 7.353 differentially expressed transcripts (DETs) for TVS and TVG, respectively. Of these DETs, 5.695 were annotated as genes (DEGs) in TVS and 4.996 in TvG (Fig. 2A). In total these DEGs include 13,5\% of all annotated gene on the microarray for TVS and $11,8 \%$ for TVG (Fig. 2A). For transcripts annotated as TEs, we identified 1.248 and 2.357 differentially expressed TEs (DETEs) in the TVS and TVG comparisons, respectively (Fig. 2B). These represent $5 \%$ of all annotated TEs on the microarray for TvS and 6,6\% for TvG (Fig. 2B).

Overall, DEGs displayed a tendency towards down regulation in Tree compared to Seedling and Graft (Fig. 2A). However, for TEs only the TvG comparison followed the same pattern, since up- and down-regulated TEs were more equally distributed in the common DETES group. DETEs specific to TVS displayed a tendency to be up regulated in Tree.

Focusing on the common DEGs between TVS and TVG, we observed two groups (Fig. 2A and C). The first group is composed of the 2.085 DEGs displaying a similar regulation pattern: 1.365 and 720 DEGs were down and up regulated in TVS and TVG, respectively. In the second smaller group, only 85 DEGs displayed an opposite trend: these transcripts were down regulated in Tree in TVS, but up regulated in Tree in TVG. Similarly, we observed two groups for DETEs (Fig. 2B and D). 277 DETEs were up regulated in Tree in both TVS and TVG, and 225 
DETEs were down regulated in Tree in both comparisons. Only 17 DETEs displayed an opposite transcript accumulation patterns compared to the general trend.

200

201

202

203

204

205

206

207

208

209

210

211

212

213

214

215

216

217

218

219

220

221

222

223

224

225

226

227

228

229

230

231

232

233

234

235

236

237

238

239

240

241

242

243

244

To study the main gene regulatory pathways represented in the differential transcription data we used the GDDH13 gene annotation of Malus domestica (v1.1) combined with the MapMan software (Lohse et al., 2014; Fig. 3A). We also considered the TE class repartition as previously described in Daccord et al., (2017) (Fig. 3B). We observed variations in class size between TVS and TvG. The most notable variations size were observed for: photosynthesis ( $9 \%$ of variation in total DEGs in TVS and only $1 \%$ in TVG), cell cycle (2\% in TVS and $9 \%$ in TVG), solute transport ( $9 \%$ in TVS and $4 \%$ in TVG), cytoskeleton ( $1 \%$ in TVS and $6 \%$ in TVG), RNA biosynthesis (13\% in TVS and $18 \%$ in TVG), RNA processing ( $2 \%$ in TVS and $6 \%$ in TVG) and chromatin organization ( $2 \%$ in TVS and $5 \%$ in TVG).

In order to identify overrepresented classes of genes that could be linked to either the adult or the juvenile phase, we performed an enrichment analysis with MapMan using our DEGs as input data (Supplemental Tab. S1). In the TvS comparison, seven functional categories were overrepresented including coenzyme metabolism, terpenoids metabolism, chromatin organization, squamosa binding protein (SBP) family transcription factor, protein biosynthesis, peptide tagging in protein degradation and enzyme classification. Eleven classes are overrepresented in the TVG comparison (Supplemental Tab. S1), including secondary metabolism, chromatin organization, cell cycle, RNA processing, protein biosynthesis, peptide tagging, cytoskeleton, cell wall, solute transport, and enzyme classification.

Next, we considered the TE class repartition in our DETE list (Fig. 3B). We did not find large variations in class repartition among the comparisons. Class I TE represented $53 \%$ of DETEs on the microarray in TVS and $46 \%$ in TVG. Concerning class II TEs we found $31 \%$ and $43 \%$ of DETEs in TVS and in TVG respectively.

Altogether, our analyses show that the two sexual and asexual tree propagation methods investigated here had a significant effect on gene and TE transcription in GDDH13.

\section{Global DNA methylation analysis of seedlings, young grafts and adult trees}

To investigate how DNA methylation marks are transmitted through mitosis as compared to meiosis, we assessed the DNA methylation levels in Seedling, Graft and Tree samples at the genome-wide level by using whole genome bisulfite sequencing (WGBS). First, we compared the genome-wide DNA methylation levels at cytosines in the three sequence contexts (CG, $\mathrm{CHG}, \mathrm{CHH}$ ). Our primary investigation indicated that there was no significant difference in cytosine methylations averages, in any of the contexts, among the tested samples (Fig. 4A). Next, we computed and identified differentially methylated regions (DMR) between Seedling, Graft and Tree. Overall, we identified 229.033 DMRs in TvS and 154.370 in TvG (Fig 4B). We also investigated DMRs close to genes (Gene-DMRs) or TEs (TE-DMRs). These DMRs are defined by their relative proximity to genes or TEs. For this purpose, we selected DMRs located within $2.000 \mathrm{bp}$ in $3^{\prime}$ or $5^{\prime}$ of annotated genes or TEs. We identified 48.651 and 18.789 Gene-DMRs in TVS and TVG, respectively. For TE, we identified 124.025 and 97.330 TE-DMRs in TVS and TVG, respectively (Fig. 4B).

We found that in each comparison, in genes, TEs or other genomic loci, DMRs were largely hypermethylated in Tree (Fig. 4B). Indeed $89 \%$ and $61 \%$ of DMRs in the three contexts were hypermethylated in TVS and in TVG respectively. Moreover, a vast majority of DMRs were 
identified in the $\mathrm{CHH}$ context (95\% and $99 \%$ in TVG and TvS, respectively; Tab. 1). Overall, DMRs tended to be hypermethylated in Tree in the $\mathrm{CHH}$ context (90\% in TvS and $63 \%$ in TVG) and hypomethylated in Tree in the CG and CHG contexts (93\% in TvS and 92\% in TVG) (Tab. 1). To identify whether DMRs were equally distributed along the genome, or were regrouped within hot spots, we computed the DMR density for the individual contexts as shown in Fig. 4C. Overall, we found that DMRs to be equally distributed all along the apple chromosomes, with some regions displaying a higher enrichment (Fig. 4C, red boxes).

In order to quantify and compare DNA methylation levels we compared DNA methylation changes $(\delta \mathrm{mC})$ within DMRs in each sequence context (Fig. 5). Overall, we identified significant differences in $\delta \mathrm{mC}$ for the $\mathrm{CHG}$ and $\mathrm{CHH}$ and not for the $\mathrm{CG}$ sequence contexts. Interestingly, in the CHG context, the $\delta m C$ value was higher in TvG (9.8\%) than in TvS (5.4\%) for hypermethylated DMRs in Tree. For hypomethylated DMRs in Tree, the $\delta \mathrm{mC}$ value was higher in TvS (9.6\%) than in TVG (8.1\%). In the CHH context, we observed that the $\delta \mathrm{mC}$ value was higher in TVS (5.8\%) than in TVG (4.9\%) for hypermethylated DMRs in Tree, and lower in TVS (3\%) than in TVG (5.8\%) for hypomethylated DMRs in Tree. From these results, we conclude that the transmission of cytosine methylation from Tree to Seed is different to the one from Tree to Graft depending on the cytosine sequence context.

For DMRs located in genic regions (Gene-DMRs, Fig. 5) we observed that there were less DMRs in the CG-CHG (359 for TVS and 390 for TVG) contexts than in the CHH context (48.292 for TvS and 18.399 for TvG). Gene-DMRs in CG and CHG context were almost all hypomethylated in Tree in both comparisons. Indeed, $99 \%$ of Gene-DMRs in the CG context were hypomethylated in both comparisons. $86 \%$ and $99 \%$ of Gene-DMRs were hypomethylated in CHG in TVS and TVG, respectively. This is consistent with the observations we made for the All-DMRs group (Tab. 1). Conversely, $96 \%$ and $62 \%$ of Gene-DMRs in the $\mathrm{CHH}$ context were hypermethylated in Tree for TVS and TVG, respectively.

While studying the DNA methylation changes, we found that in the CG and CHH contexts, the $\delta \mathrm{mC}$ values of hypomethylated Gene-DMRs were smaller in TVS (3.0 and $4.2 \%$ respectively) than in TVG (4.8 and $8.2 \%$ respectively). However, for hypomethylated GeneDMRs in the $\mathrm{CHG}$ and $\mathrm{CHH}$ contexts in Tree the $\delta \mathrm{mC}$ value was higher in TvS $(8.0$ and $7.7 \%$ respectively) than in TvG (5.8 and 8.2\% respectively) following the overall trend observed for All-DMRs. These observations indicate towards a contrasted sequence context specific pattern of DNA methylation differences.

For DMRs located in TE annotations (TE-DMRs, Fig. 5), our observations were similar to the results for Gene-DMRs. Overall most TE-DMRs were hypomethylated in Tree in the CG (76\% for TVS and $88 \%$ for TVG) and CHG $(65 \%$ for TVS and $77 \%$ for TVG) contexts, and hypermethylated in the $\mathrm{CHH}$ ( $87 \%$ for TVS and $64 \%$ for TVG) context. We did not find significant differences in $\delta \mathrm{mC}$ values for the CG context. For TEs, the $\delta \mathrm{mC}$ value of hypermethylated TE-DMRs was smaller in TVS (6.2 and 5.6\% respectively) than in TVG (10.3 and $6.5 \%$ respectively) and higher for hypomethylated TE-DMRs in TVS (10.4 and 6.2\% respectively) as opposed to TvG (8.4 and $6.0 \%$ respectively). 
Even though there were no strong global differences in DNA methylation level between the samples analyzed here, we found significant local differences. The majority of DMRs were in the $\mathrm{CHH}$ context with a tendency to be hypermethylated in Tree.

\section{Classes of genes enriched with DMRs}

To identify genes belonging to particular functional categories and presenting DMRs in their proximity, we used the aforementioned GDDH13 annotation in MapMan and the TE annotation as previously used in our transcriptomic analysis. Here we only considered GeneDMRs and TE-DMRs in the CHH context. We excluded DMRs associated with the CG and CHG context here analysis due of their very limited number (Supplemental Tables S2 and S3). For the following, we termed as DEG-DMRs genes that we found to be differentially transcribed and containing or being close to DMRs. Similarly, TEs identified as DETEs and being associated with TE-DMRs were termed DETE-DMRs.

As expected, we found the seven classes that we previously identified in DEGs analysis: RNA biosynthesis, protein modification, enzyme family, protein degradation, solute transport, photosynthesis and protein biosynthesis (Fig. 6A). We did not find differences in the proportion of gene classes between TVS and TVG.

308 For DETE-DMRs (Fig. 6C) we observed a smaller proportion of Class I TEs in TVG $(57,4 \%)$ compared to TVS (77,7\%), while for class II TEs we found $35.4 \%$ for TVG and $15.5 \%$ for TVS.

\section{Relationship between DNA methylation and transcription}

Next, we associated Gene- and TE-DMRs to our microarray transcriptome data and the aforementioned gene classes are defined according to the Mapman annotation of genes and to the TE annotation previously used to analyze DEGs and DETEs. For this analysis we applied a threshold and kept only transcripts with differential expression ratios above 1.5 and below -1.5 in order to better identified pathways or genes to work with. We found 520 DEG-DMRs in TVS and 115 DEG-DMRs in TVG (Fig. 6C), 35 DETE-DMRs in TVS and 38 DETE-DMRs in TVG (Fig. 6D). We investigated genes and TEs classes' repartition for DEG- and DETE-DMRs. Of the eleven classes found in DEGs analysis (Fig. 3A), here, we found only six gene classes representing only slightly more than $5 \%$ of all DEG-DMRs. These including the classes photosynthesis, RNA biosynthesis, enzyme family, protein biosynthesis, RNA processing and cytoskeleton (Fig.6B).

We did not observe notable shifts within the classes' repartition between TvS an TvG for DETE-DMRs (Fig. 6D).

Finally, we investigated the link between DMRs and DEGs. As previously we only considered DEG-DMR in the CHH context because of the low number of DEG-DMR we found in the CG and CHG context. We noticed that in both comparisons the majority of DMRs in DEG-DMRs were located in gene promoters (539 for TVS and 114 for TVG), followed by terminator region ( 284 for TVS and 58 for TVG) finally followed by those present in gene bodies (139 for TvS and 42 for TVG) (Fig. 7A, 7B. See examples of these DEG-DMRs in Supplemental fig. S2). Our data also indicate that, independently of the DMR position relative to a gene, hypermethylated DMRs were associated with a gene down-transcription in the Tree sample (Fig. 7A \& B).

Among the classes of differentially transcribed genes associated with DMRs, we observed that genes associated with photosynthesis were mostly both hypermethylated and 
bioRxiv preprint doi: https://doi.org/10.1101/818690. this version posted October 25. 2019. The copyriaht holder for this preprint (which was not certified by peer review) is the author/funder, who has granted bioRxiv a license to display the preprint in perpetuity. It is made available under aCC-BY-NC 4.0 International license.

336 downregulated in the Tree sample. Indeed 92\% of Gene-DMRs associated to photosynthesis pathway present this pattern in TVS and $100 \%$ of them in TVG. Our results indicate that in the $\mathrm{CHH}$ context, hypermethylation of a DNA sequence in the proximity of a gene reduce the level of transcription of that particular gene. 


\section{Discussion}

Newly grafted plants are at an intermediate state between adult tree and juvenile seedling Phenotypic differences between juvenile and adult plants are commonly observed at the leaf level (Lavee et al. 1996). In our study we observed that leaves of seedlings displayed a low trichome density compared to grafted plants and to the donor tree (Fig. 1). As previously reported by others, this phenotype can be associated to the juvenile phase (Basheer-Salimia 2007) and the grafted plant seems thus closer to the adult tree than to the juvenile seedling from that point of view. Nonetheless, newly grafted plants show a contrasted ability to flower. In the grafting process, a mature bud (able to flower or quiescent) is placed on a short-rooted stem (rootstock). The number of nodes between the apical bud and the rootstock is drastically reduced to 1 or 2 nodes. After their first year of growth, buds are in a mature adult state but are unable to initiate flowers and to bear fruits because of an insufficient number of nodes (less than 77 ) in the stem, a limit previously described as a transition phase between juvenile and adult apple tree (Zimmerman 1973; Hanke et al. 2007; X. Z. Zhang et al. 2007).Thus, grafted plants are not adult plants from a physiological point of view.

Here, we wanted to study the molecular changes that occur during propagation via grafting and by seed formation. First, we compared the transcription profiles in three different stages: seedlings, grafted plants and the donor tree, taking advantage of our genetically identical material growing under highly similar conditions. Globally we observed a lower transcription level for the majority of the DEGs and DETEs in the adult tree compared to grafts or seedlings. This correlates well with the previously reported decrease in gene transcription in mature plants, compared to juvenile plants (Murray, Smith, and Hackett 1994; Hand et al. 1996; Ryan, Binkley, and Fownes 1997). Furthermore, the common DEGs identified in Tree versus Seedling and Tree versus Graft comparisons as repressed could be correlated to high vegetative growth in younger stages such as seedlings and grafted plants, and thus be transcribed at a lower level in mature apple tree, as observed in Day, Greenwood and DiazSala, (2002) (Day, Greenwood, and Diaz-Sala 2002). Thus, the transcriptome of newly grafted plants showed similarities with the one obtained from seedlings but also with adult trees. These observations are in line with previous studies on other woody plant (Murray, Smith, and Hackett 1994; Hand et al. 1996; Ryan, Binkley, and Fownes 1997; Day, Greenwood, and Diaz-Sala 2002).

Overall, our findings indicate that young grafted plants are at the interface between a juvenile seedling and an adult mature tree (Zimmerman 1973; Hanke et al. 2007) from a morphological and transcriptomic perspective.

This intermediate condition of newly grafted plants is confirmed from a physiological point of view. Indeed, we identified differences in gene class repartition of DEGs between TVS and TVG (Fig. 3A) which included classes photosynthesis, RNA processing, chromatin organization and cell cycle. And concerning genes related to photosynthesis we found that they represented $9 \%$ of DEGs in TVS but only $1 \%$ in TVG. This is consistent with the fact that the photosynthetic pathway has previously been described as differentially regulated between juvenile and mature reproductive plant, especially in woody plants (reviewed in Bond, 2000), and is known as a physiological process subjected to many modifications from juvenile to mature phase (Greenwood 1995). As juvenile, seedlings undergo broader transcriptomic changes compare to grafts and trees. This can be associated to an age-related gene transcription pattern previously described for photosynthesis related genes in other woody plant such as Pinus taeda (Greenwood 1984), Larix laricina (Hutchison et al. 1990), Picea 
rubens (Rebbeck, Jensen, and Greenwood 1993) and in Quercus gender (McGowran, Douglas, and Parkinson 1998).

This intermediate condition of newly grafted plants between juvenile seedlings and adult tree was also observed at specific loci at the DNA methylation level in the $\mathrm{CHH}$ context. Indeed, overall a hypermethylation of the $\mathrm{CHH}-\mathrm{DMRs}$ was observed in trees compared to grafts, which was less extended (62\% in TVS) compared to the nearly total hypermethylation of CHH-DMRs observed in the Tree sample compare to Seedlings (96\% in TVG).

\section{DMRs influence neighboring gene transcription}

398 Previous reports established a correlation between DNA methylation and the repression of 399 gene transcription, particularly in the model plant Arabidopsis (X. Zhang et al. 2006; 400 Zilberman et al. 2007). In this study, we investigated a possible link between DNA 401 methylation and gene transcription changes in $M$. domestica. For that purpose, we 402 associated DMRs with their neighboring DEG in order to investigate the effect of methylation 403 on gene transcription. We found that in the $\mathrm{CHH}$ context, genes with closely located 404 hypermethylated DMRs (in Tree sample) often displayed a lower gene transcription level in 405 Trees compared to Seedlings or Grafts (Fig. 7). This was particularly the case for 406 photosynthesis related genes (Fig. 7). Our data indicate thus that cytosine methylation in 407 the $\mathrm{CHH}$ context seems to be involved in regulating the transcription of these genes.

408 We did not only observe local changes in DNA methylation, but also contrasted levels of DNA 409 methylation changes $(\delta \mathrm{mC})$. Indeed, we found significant differences at the $\delta \mathrm{mC}$ level 410 between both comparisons, particularly in the $\mathrm{CHG}$ and $\mathrm{CHH}$ contexts (Fig. 5). For 411 methylation in the $\mathrm{CHH}$ context, we observed that, even if the difference in $\delta \mathrm{mC}$ was significant between TVS and TVG, it is not very high between the comparisons but also within comparisons. Indeed, the highest $\delta \mathrm{mC}$ was on average above $8 \%$ for hypomethylated GeneDMRs in TvG. But we also found that this relatively small methylation variation was enough to find relationship with gene transcription changes (Fig. 7). 


\section{Conclusion}

418 In this study we compared the transmission of epigenetic marks and their potential effects

419 on transcription during sexual and asexual reproduction in apple.

420 First, we identified a phenotypic change (Fig. 8) that was associated with adult plant phase 421 and confirmed that grafting is not comparable to a complete rejuvenation process, as 422 observed in seedlings. In our transcriptomic analysis we showed gene level transcription 423 differences of the tree compared to seedlings and grafts (Fig. 8). In particular, we found that 424 the transcription level of genes related to photosynthesis was relatively high in seedlings 425 compared to the tree, while newly grafted plants displaying an intermediate transcription 426 level (Fig. 8).

427 Analysis of the methylation data indicated that at the genome scale, the level of methylation 428 in all three samples was similar. However, we were able to identify DMRs particularly in the $429 \mathrm{CHH}$ context. This result indicates that methylation reprogramming during meiosis may not 430 affect the global methylation level of the genome, but rather modify particular regions of the 431 genome, presumably allowing the seedling to increase its competitiveness. This observation was particularly striking regarding genes associated with photosynthesis. As found in transcriptomic analysis, the methylome data indicated that grafted plants were at the 434 interphase between the tree and the seedlings.

435 Globally, our results indicate that, from a physiological, transcriptomic and epigenomic 436 standpoint, newly grafted plants are at the interphase between a tree and a seedling, 437 displaying characteristics that are particular to both the mature and the young immature 438 stages of the plant. 


\section{Materials and Methods}

440

441

442

443

444

445

446

447

448

449

450

451

452

453

454

455

456

457

458

459

460

461

462

463

464

465

466

467

468

469

470

471

472

473

474

475

476

477

478

479

480

481

482

483

484

485

\section{Plant material}

Malus domestica materials were obtained from 'GDDH13' (Lespinasse et al. 1999) line (X9273). Grafted plant (called "Graft" in this paper) materials were obtained by grafting budwood of 'GDDH13' orchard tree (2001) on the rootstock 'MM106'. Seedling materials (called "Seedling" in this paper) were obtained by self-fertilization of 'GDDH13' tree in 2017. Seed dormancy was removed by 3 months of cold stratification before sowing. Homozygous state of seedling was confirmed by PCR, using SSR markers on the seedling samples used in this work. A clone of the original 'GDDH13' from orchard, grafted onto an MM106 rootstock in 2007 and placed in the greenhouse in 2016 was used as reference mature adult tree (called "Tree" in this paper).

\section{Phenotyping}

Nine young leaves were harvested for each sample and time point. At each sampling time Seedling and Graft plants were pruned to increase vigor. Three replicates were made at three weeks intervals for Graft and Seedling materials in 2018, and one replicate was made in 2019 including Tree material (twelve leaves were sampling). Each leaf was then photographed under binocular magnifier (Olympus SZ61, Schott KL 1500 LED, Olympus DP20). Pictures were further analyzed with the Image ${ }^{\circledR}$ software (Schneider, Rasband, and Eliceiri 2012). Pictures were transformed in 8-bit grayscale and light intensity was measured on 5 areas of $0.03 \mathrm{~cm}^{2}$ on each leaf. Intensity differences between samples were evaluated using the R language by Kruskal-Wallis test. We first compare biological replicates from 2018 and from 2019 (Seed and Graft). Because there were no differences between biological replicates of Seedling from 2018 and 2019 and similarly to Graft sample from 2018 and 2019, we decide to only present result of the 2019 year which include Tree sample.

\section{DNA and RNA extraction}

The youngest and completely opened leaf was sampled for each replicate. Sampling was performed as described in Table S4. The DNA was extracted using NucleoSpin Plant II kit (Macherey-Nagel, Hoerdt, France). The manufacturer's recommendations were applied with the next modifications: at step 2a PL1 buffer quantity was raised to $800 \mu \mathrm{L}$ and PVP40 was added at $3 \%$ of final volume, suspension was then incubated $30 \mathrm{~min}$ at $65^{\circ} \mathrm{C}$ under agitation. The lysate solution was centrifuged $2 \mathrm{~min}$ at $11000 \mathrm{~g}$ before transferring the supernatant in step 3. At step 4 PC buffer was raised to $900 \mu \mathrm{L}$. In step 6 the first wash was decreased to $600 \mu \mathrm{L}$ and the third wash was raised to $300 \mu \mathrm{L}$. An extra-centrifuge step was added after washing to remove ethanol waste from the column. In step 7 DNA was eluted twice in $55 \mu \mathrm{L}$ in total. The RNA was extracted using the NucleoSpin ${ }^{\circledR}$ RNA kit (Macherey-Nagel, Hoerdt, France) according the manufacturer's protocol.

\section{Bisulfite sequencing and DMRs calling}

Extracted DNA was precipitated in pure ethanol (70\%), water (24\%) and NaAc 3M (3\%). After precipitation DNA was sent to Beijing Genomics Institute (Shenzhen, Guangdong 518083, China) in pure ethanol for whole genome bisulfite sequencing. DNA methylation data can be accessed on the Gene Expression Omnibus website under accession codes GSE138377. Bisulfite sequencing reads were mapped on GDDH13_V1.1 reference genome with Bsmap tool (Xi and Li 2009) to obtain methylation calling file. Methylation averages between samples were compared by student test using R (R Core Team 2016). 
We called differentially methylated regions (DMRs) using a hidden Markov model (HMM)based (Hagmann et al. 2015) approach as in Daccord et al., (2017). DMRs were calculated between Tree and Seedling samples and between Tree and Graft samples with the following parameters: coverage of $3,200 \mathrm{bp}$ sliding windows with $100 \mathrm{bp}$ overlapping. DMRs files contain quality values such as p-value, average of standard deviation (SDA) and methylation differences. We empirically determined a threshold for each context using the DMR preview on a local JBrowse (Buels et al. 2016). This threshold was determined on SDA value (Supplemental tab. S5). Thresholds were determined in order to select the most reproducible DMRs within biological replicates (Supplemental tab. S6).

\section{Microarray}

The Malus domestica array (Agilent-085275_IRHS_Malus_domestica_v1; GPL25795; Agilent, Foster City, CA, USA) was used for microarray analysis. Complementary DNA (CDNA) were synthesized and hybridized with the Low Input Quick Amp Labeling Kit, two-color (Agilent, Foster City, CA, USA). Two biological replicates were used. Each biological replicate represents one sample for Tree and Graft materials, and a pool of two samples for Seedling material. Hybridizations were performed on a NimbleGen Hybridization System 4 (mix mode B) at $42^{\circ} \mathrm{C}$ overnight. Slides were then washed, dried, and scanned at $2 \mu \mathrm{m}$ resolution. NimbleGen MS 200 v1.2 software was used for microarray scans, and the Agilent Feature Extraction 11.5 software was used to extract pair-data files from the scanned images. We used the dye switch approach for statistical analysis as described in Depuydt et al., (2009). Analyses were performed using the $R$ language (R Development Core Team, 2009); data were normalized with the lowess method, and differential transcription analyses were performed using the ImFit function and the Bayes moderated $\mathrm{t}$ test using the package LIMMA (Smyth, Michaud, and Scott 2005). Transcriptomic data are available in Gene Expression Omnibus website, with the accession GSE138491.

\section{$R T$-QPCR microarray validation}

Extracted mRNA was treated by DNAse with the RQ1 RNase-Free DNase (Promega, Madison, WI, US) following the manufacturer's protocol. The Moloney Murine Leukemia Virus Reverse Transcriptase was used to obtain cDNA from $1,2 \mu \mathrm{g}$ of total RNA, with oligot(dT) primers following the manufacturer's protocol (Promega, Madison, WI, USA). For QPCR measurements, 2,5 $\mu \mathrm{L}$ of cDNA at the appropriate dilution were mixed in a final volume of $10 \mu \mathrm{L}$ with $5 \mu \mathrm{L}$ of quantitative PCR mastermix (MasterMix Plus for SYBR Green I with fluorescein; Eurogentec EGT GROUP, Seraing, Belgium), with $0.2 \mu \mathrm{L}$ of each primer (200nM final) and with $4,1 \mu \mathrm{L}$ of pure water. Primers were designed with Primer3Plus (Untergasser et al. 2007) and were used at their optimal concentration found thanks to reaction efficiency calculation (near to 100\%) according to Pfaffl recommendations (Pfaffl 2001). Genes selected to validate the microarray data were selected in DEG lists in both comparisons (TVS and TVG) with 1) a high ratio value and 2) high intensities values. Accessions and primer sequences are indicated in figureS3A. Reaction was performed with a CFX connect Real time system (BioRad, Hercules, CA, USA) using the following program: $95^{\circ} \mathrm{C}, 5 \mathrm{~min} ; 35$ cycles comprising $95^{\circ} \mathrm{C}$ for $3 \mathrm{~s}, 60^{\circ} \mathrm{C}$ for $45 \mathrm{~s} ; 65^{\circ} \mathrm{C}, 5 \mathrm{~s}$ and $90^{\circ} \mathrm{C}$ for $1 \mathrm{~min}$, with real-time fluorescence monitoring. Melt curves were acquired at end of each run. Data were acquired and analyzed with CFX Maestro V1.1 (Bio- Rad, Hercules, CA, USA). Gene transcription levels were calculated using the $2^{-\Delta \Delta C t}$ method and were corrected as recommended by Vandesompele et al., (2002) (Supplemental fig. S3B), with three reference genes: Actin (accession CV151413, 
533 MD14G1142600), Gapdh (accession CN494000, MD16G1111100), and Tubulin (accession

534 CO065788, MD03G1004400) used for the calculation of a normalization factor.

Differentially express transcript (DET) analysis

537 Differentially expressed transcripts were selected based on their $p$-value $\leq 1 \%$ (Supplemental

538 tab. S7). For DET other than TE and miRNA a MapMan annotation 539 (https://mapman.gabipd.org/home; version 3.5.0BETA), was performed, using GDDH13_1540 1_mercator4 map file, in order to assign each DET to a BIN. DET not assigned to a BIN class 541 were excluded. A representativeness percentage of each BIN class was then calculated in the 542 comparisons TVS, TVG and in the intersection between the both comparisons. A MapMan 543 enrichment analysis on the BIN class representativeness was performed and a BH correction 544 was applied (Benjamini and Hochberg 1995) because of the high number of values. For 545 DETEs, the TE classification (Daccord et al. 2017) was used in order to assign each DETE to a 546 class.

547

Association between DMR and DEG or DETE

549 DMRs and transcription level data (DEG or DETE) results were connected thanks to gene 550 identifier. DMRs without associated DETs were removed. There is some redundancy of the 551 gene or TE identification because many DMRs could be close. To avoid biases in our analysis 552 we only kept DMR with the highest methylation variation to each gene or TE (Supplemental 553 tab. S8).

554

\section{Accession numbers:}

556 GSE138492: global depository accession number comprising methylome and transcriptome 557 data

558 GSE138377: bisulfite sequence data and methylation calling files

559 GSE138491: microarray data

560

561

\section{Large datasets:}

562 Supplemental table S6: DMRs list of TvS and TVG comparisons, including Gene- and TE-DMRs. 563 Supplemental table S7: DETs list of TVS and TVG comparison

564 Supplemental table S8: DEG- and DETE-DMRs list of TVS and TvG comparisons

Acknowledgements: M. ORSEL-BALDWIN for GDDH13_1-1_mercator4 files processing. 567 Region Pays de la Loire (FRANCE) to funding this work. 
569 Table 1: DMR distributions according to context and methylation changes. Number and 570 percentage of hyper- and hypomethylated DMR in Tree sample in each comparison (TvS and 571 TVG).

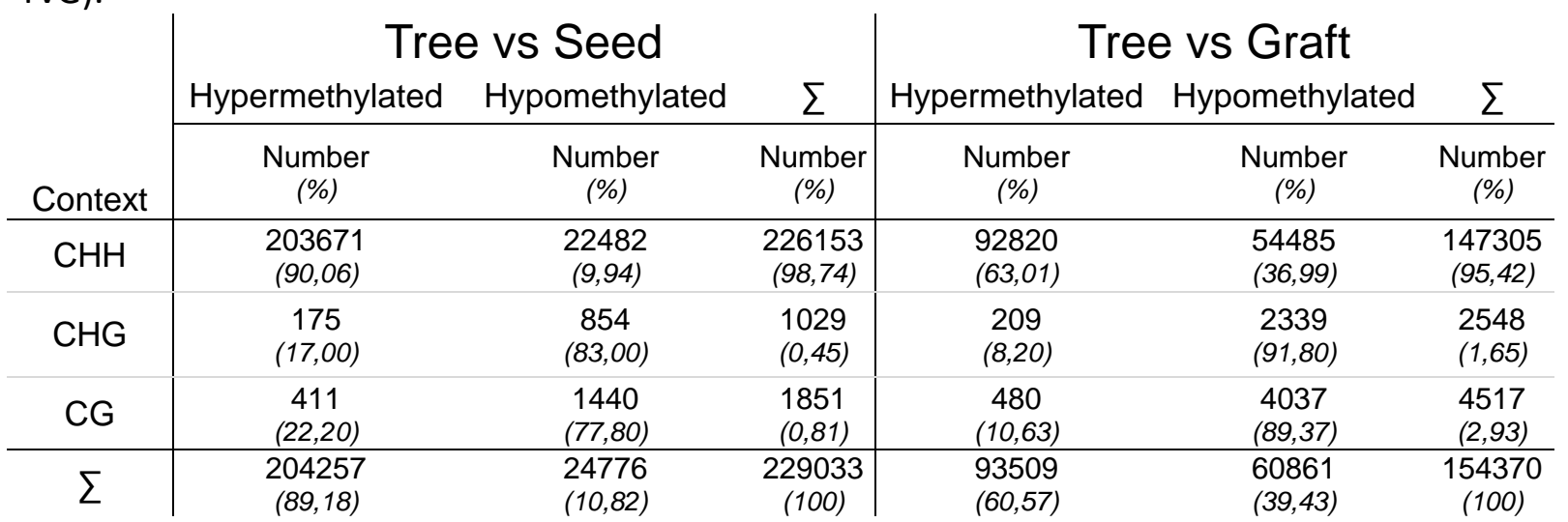

574 Supplemental table S1: Functional classes found in enrichment analysis on Mapman 575 software. In red are indicate number of DEGs over transcribed in Tree sample, down 576 regulated are in blue. "p-value" correspond to the p-value obtained in the enrichment 577 analysis and corrected by the $\mathrm{BH}$ method.

\begin{tabular}{|c|c|c|c|c|c|c|c|c|c|c|c|}
\hline \multirow{2}{*}{ Category name } & \multirow{2}{*}{ Bincode } & \multicolumn{3}{|c|}{ Tree vs Seed } & \multicolumn{3}{|c|}{ Tree vs Graft } & \multicolumn{4}{|c|}{ Commons } \\
\hline & & Up & Down & $p$-value & Up & Down & $\mathrm{p}$-value & Up & Down & other & p-value \\
\hline $\begin{array}{l}\text { Coenzyme metabolism } \\
\text { Secondary metabolism / terpenoids }\end{array}$ & $\begin{array}{l}7 \\
9.1\end{array}$ & $\begin{array}{l}0 \\
2\end{array}$ & $\begin{array}{l}19 \\
11\end{array}$ & $\begin{array}{l}2.56 \mathrm{E}-05 \\
5.43 \mathrm{E}-03\end{array}$ & & & & 1 & 3 & & 1.59E-02 \\
\hline $\begin{array}{l}\text { Secondary metabolism / phenolics / } \\
\text { p-coumaroyl-coa synthesis }\end{array}$ & 9.2 .1 & & & & 0 & 2 & $7.50 \mathrm{E}-03$ & & & & \\
\hline $\begin{array}{l}\text { Chromatin organization } \\
\text { Cell cycle }\end{array}$ & $\begin{array}{l}12 \\
13\end{array}$ & 19 & 3 & 2.48E-05 & $\begin{array}{l}1 \\
5\end{array}$ & $\begin{array}{l}14 \\
39\end{array}$ & $\begin{array}{l}6.03 \mathrm{E}-03 \\
9.05 \mathrm{E}-04\end{array}$ & & & & \\
\hline Rna biosynthesis / transcriptional activation / SBP transcription factor & 15.7.18 & 8 & 0 & 3.37E-03 & & & & & & & \\
\hline $\begin{array}{c}\text { Rna biosynthesis / organelle machinreies } \\
\text { Rna processing }\end{array}$ & $\begin{array}{c}15.9 \\
16\end{array}$ & & & & 5 & 30 & 3.53E-03 & 1 & 5 & & $1.50 \mathrm{E}-02$ \\
\hline Protein biosynthesis & 17 & 9 & 40 & $3.17 \mathrm{E}-03$ & 5 & 29 & $2.90 \mathrm{E}-04$ & 5 & 53 & & 4.07E-12 \\
\hline $\begin{array}{l}\text { Protein modification / phosphorylation / } \\
\text { TKL kinase superfamily }\end{array}$ & 18.8 .1 & & & & & & & 1 & 9 & 1 & $6.55 \mathrm{E}-03$ \\
\hline Protein degradation / peptide tagging & 19.4 & 18 & 15 & 7.94E-03 & 16 & 7 & $5.10 \mathrm{E}-04$ & & & & \\
\hline $\begin{array}{l}\text { Protein degradation / peptidase families / serine-type peptidase } \\
\text { activities }\end{array}$ & 19.5 .2 & & & & & & & 1 & 9 & 1 & 8.33E-04 \\
\hline $\begin{array}{c}\text { Cytoskeleton } \\
\text { Cell wall }\end{array}$ & $\begin{array}{l}20 \\
21\end{array}$ & & & & $\begin{array}{c}1 \\
13\end{array}$ & $\begin{array}{c}20 \\
0\end{array}$ & $\begin{array}{l}1.04 \mathrm{E}-06 \\
1.58 \mathrm{E}-05\end{array}$ & & & & \\
\hline $\begin{array}{c}\text { Protein translocation / chloroplast / thylakoid membrane SRP } \\
\text { insertion system }\end{array}$ & 23.1 .7 & & & & & & & 1 & 7 & 1 & $1.50 \mathrm{E}-02$ \\
\hline Solute transport & 24 & & & & 16 & 1 & $3.12 \mathrm{E}-06$ & & & & \\
\hline Enzyme classification & 50 & 30 & 84 & 4.24E-03 & 31 & 25 & 7.32E-03 & & & & \\
\hline Not assigned & 35 & & & & 235 & 617 & $7.50 \mathrm{E}-03$ & 122 & 252 & 14 & 1.17E-02 \\
\hline
\end{tabular}

580 Supplemental table S2: Count of DEG-DMRs in TvS and TvG comparisons. Here we included

581 the unclassified gene class "35" not present in Fig. 6.

\begin{tabular}{c|c|ccc|cc|c}
\multirow{2}{*}{ Context } & \multicolumn{3}{|c|}{ Tree vs Seed } & \multicolumn{3}{c}{ Tree vs Graft } \\
\cline { 2 - 8 } & localization & Hypermethylated Hypomethylated & $\Sigma$ & Hypermethylated Hypomethylated & $\Sigma$ \\
\hline \multirow{3}{*}{$\mathrm{CHH}$} & head & 1394 & 55 & 1449 & 406 & 261 & 667 \\
& body & 295 & 21 & 316 & 137 & 70 & 207 \\
& tail & 684 & 31 & 715 & 228 & 137 & 365 \\
\hline \multirow{3}{*}{$\mathrm{CHG}$} & head & 0 & 2 & 2 & 0 & 3 & 3 \\
& body & 1 & 5 & 6 & 0 & 2 & 2 \\
& tail & 0 & 4 & 4 & 0 & 3 & 3
\end{tabular}




\begin{tabular}{c|c|ccc|ccc|c}
\multirow{3}{*}{ CG } & head & 1 & 5 & 6 & 0 & 7 & 7 \\
& body & 3 & 4 & 7 & 0 & 4 & 4 \\
& tail & 1 & 4 & 5 & 0 & 10 & 10 \\
\hline & $\Sigma$ & 2379 & 131 & 2510 & 771 & 497 & 1268
\end{tabular}

Supplemental table S3: Count of DETE-DMRs in CHH context in TvS and TvG comparisons.

\begin{tabular}{c|c|ccc|ccc}
\multirow{2}{*}{ Context } & \multicolumn{3}{|c|}{ Tree vs Seed } & \multicolumn{3}{c}{ Tree vs Graft } \\
\cline { 3 - 8 } & localization & Hypermethylated Hypomethylated & $\Sigma$ & Hypermethylated Hypomethylated & $\Sigma$ \\
\hline \multirow{3}{*}{$\mathrm{CHH}$} & head & 0 & 0 & 0 & 0 & 0 & 0 \\
& body & 115 & 22 & 137 & 153 & 113 & 266 \\
& tail & 10 & 1 & 11 & 5 & 6 & 11 \\
& head & 0 & 0 & 0 & 0 & 0 & 0 \\
$\mathrm{C} H G$ & body & 0 & 3 & 3 & 1 & 28 & 29 \\
& tail & 0 & 0 & 0 & 1 & 0 & 1 \\
\hline \multirow{3}{*}{$\mathrm{CG}$} & head & 0 & 0 & 0 & 0 & 0 & 0 \\
& body & 1 & 6 & 7 & 1 & 22 & 23 \\
& Tail & 0 & 0 & 0 & 0 & 1 & 1 \\
\hline \multirow{5}{*}{} & $\Sigma$ & 126 & 32 & 158 & 161 & 170 & 331
\end{tabular}

Supplemental table S4: Resume of defined samples and details of sampling

\begin{tabular}{|c|c|c|c|c|c|c|c|c|}
\hline Sample & $\begin{array}{c}\text { Way of } \\
\text { multiplication }\end{array}$ & $\begin{array}{l}\text { Years of } \\
\text { obtention }\end{array}$ & $\begin{array}{c}\text { Years } \\
\text { sampling }\end{array}$ & $\begin{array}{l}\text { Numbers } \\
\text { sample }\end{array}$ & Pooled & $\begin{array}{l}\text { Numbers } \\
\text { leaves per } \\
\text { sample }\end{array}$ & $\begin{array}{l}\text { Numbers } \\
\text { leaves sampled } \\
\text { per tree }\end{array}$ & $\begin{array}{c}\text { Numbers } \\
\text { sampled trees }\end{array}$ \\
\hline Tree & $\begin{array}{l}\text { Grafting } \\
\text { (Asexual) }\end{array}$ & 2005 & 2016 & 3 & Yes & 4 & 4 & 1 \\
\hline Seed & $\begin{array}{l}\text { Seedling } \\
\text { (Sexual) }\end{array}$ & 2016 & 2016 & 4 & No & 1 & 1 & 4 \\
\hline Graft & $\begin{array}{l}\text { Grafting } \\
\text { (Asexual) }\end{array}$ & 2016 & 2016 & 2 & Yes & 10 & 1 & 20 \\
\hline
\end{tabular}

590 Supplemental table S5: Fixed threshold to filter DMRs calculated between each 591 comparison. Threshold were empirically fixed by observation of methylation calling file in 592 the Jbrowse software.

\begin{tabular}{c|ccc|c} 
DMRs & \multicolumn{2}{|c|}{ Standard deviation average threshold } & p-value \\
& Tree & Seed & graft & (1\% \\
\hline CG - CHG & 0,07 & 0,11 & 0,07 & \multirow{2}{*}{ CHH } \\
\hline
\end{tabular}


Figure legends:

Figure 1: Leaf trichome density comparisons between seedlings, grafted plants and parental tree. Leaf pictures indicate visual differences in trichome density for seedlings $(A)$, grafts (B) and donor tree (C). The graph in (D), represents results from light intensity measurements carried out on the abaxial face of leaves. High light intensity correlates with high trichome density. $\mathrm{N}=60$ (5 measures on 12 leaves) per sample. Statistical differences were evaluated by a Kruskall-Wallis test two by two. Asterix p-value: ***: $1 \%$.

Figure 2: Transcriptome comparisons between seedling, grafts and donor tree. Graphical representation of the number of differentially expressed transcripts in the different comparisons. (A) Venn diagram showing differentially transcribed genes (DEGs) in the comparisons TVS and TVG. (B) Venn diagram depicting differentially expressed TEs (DETEs) in the comparisons TVS and TVG. The central number in brackets represent common DETs displaying alternative pattern of transcriptional regulation. In (C) and (D) the heat maps depict transcription ratios of common DEGs (C) and DETEs (D). Numbers of DETs in each heat map are indicated below it. Fold change ratios are shown in the color scale bar.

Figure 3: Classification of differentially expressed transcripts. (A) percentage of DEGs in each comparison in function of the gene classification according to Lohse et al. (2014). (B) percentage of DETEs in each comparison in function of TEs classification according to Daccord et al. (2018). Classes represented by less than $5 \%$ in the three condition were summed up in "Other class".

Figure 4: Global overview of DNA methylation differences between seedlings, grafts and trees. (A) Histogram presenting the genome wide cytosine methylation level (in percentage) of the three methylations context ( $\mathrm{CG}, \mathrm{CHG}$ and $\mathrm{CHH}$ ). Student test was performed to evaluate differences and the results $(B, C$ and $D)$. Histograms representing the number of DMRs for each comparison: hypermethylated (above 0 , in blue) or hypomethylated (below 0 , in orange) in the Tree samples for all DMRs (B), Gene-DMRs (C) and TE-DMRs (D). DMRs in all contexts were counted and values are indicated in graph. (E) density plot of number of DMRs in $50 \mathrm{~kb}$ windows on the GDDH13 genome for TVS (see supplemental figure S1 for TVG). In red, DMRs in the CG context, in blue for the CHG context and in orange the $\mathrm{CHH}$ context. Each point represents the number of DMRs in a $50 \mathrm{~kb}$ window of the genome. Red dashed boxes indicate the presence of DMR hot spots.

Figure 5: Levels of DNA methylation changes in gene and TE annotations. Histograms depicting DMRs methylation variations $(\delta \mathrm{mC})$ between samples separated by sequence context and functional annotation. All DMRs are presented in the All-DMRs column, genes and TEs in the Gene-DMRs and TE-DMRs, respectively. DMRs were filtered by $p$-value and SDA (standard deviation average) in accordance to a fixed threshold (Table S2). Student test was performed to evaluate differences in $\delta \mathrm{mC}$, results are represented by an asterix depending on the $\mathrm{p}$-value threshold: *: $5 \%{ }^{* *}: 1 \%{ }^{* * *}: 1 \%$. $\delta \mathrm{mC}$ : delta of methylation. The Tree sample was taken as reference to define the hyper- or hypomethylated state of DMRs.

Figure 6: Classification of differentially expressed genes that are associated to DMRs. Histograms describing the percentage of DEG-DMRs ( $A$ and $B$ ) and DETE-DMRs ( $C$ and $D)$ in the respective comparisons in function of gene or TEs classification. Only DMRs in the $\mathrm{CHH}$ context are presented here. In (A) and (C) all DEGs- and DETEs-DMRs were used while in (B) and $(D)$ we only considered DEGs and DETEs with differential transcription ratio greater than 
6391.5 in absolute value. Gene classes representing less than $5 \%$ (A) or $10 \%$ (B) of the total in

640 the three conditions were summed up in "other class".

641 Figure 7: Relationship between transcription ratio and DNA methylation variation

642 Scatterplot representing DEG-DMRs in TVS (A) and TVG (B) in the CHH context, X axis 643 represents $\delta m C$ and $Y$ axis represents gene expression ratios. In blue/orange are shown all 644 DEG-DMRs and in black the ones specifically associated to photosynthesis. Numbers of DEG645 DMRs used in each graph are indicated in the legend and percentages indicate number of 646 DEG-DMRs in each corner of the graph. We separated DEG-DMRs in function of the position 647 of the DMRs related to the corresponding gene (head = promoter, body, tail = terminator). 648 Here we included the unannotated gene class "35" not present in Fig. 6.

649 Figure 8: General overview of the main results of this study concerning physiological and 650 molecular changes occurring during sexual and an asexual multiplication. The red dot 651 represents the grafting point between scion and rootstock (larger line weight). Shared aspect 652 between plants are highlighted by background colours.

653 Supplemental figure S1: Methylation overview in GDDH13. Density plot of DMRs on all 654 GDDH13 genome in TvG. In red, DMRs in CG context, in blue CHG and in orange $\mathrm{CHH}$. Each 655 point represent number of DMRs in $50 \mathrm{~kb}$ windows of genome.

656 Supplemental figure S2: Jbrowse screenshoot of two DEG-DMRs present in scatterplot (fig 657 7A) with DMRs in the promotor of genes highlight by a red dashed boxe.

658 Supplemental figure S3: (A) Q-PCR primers for micro array data validation. Indicated ratios 659 came from micro array data in both comparisons. (B) Q-PCR validation of micro array data. 
661

662

663

664

665

666

667

668

669

670

671

672

673

674

675

676

677

678

679

680

681

682

683

684

685

686

687

688

689

690

691

692

693

694

695

696

697

698

699

\section{LITERATURE CITED}

Agrawal, Anurag A., Sharon Y. Strauss, and Michael J. Stout. 1999. “Costs of Induced Responses and Tolerance to Herbivore in Male and Female Fitness Components of Wild Radish." Evolution. http://www.eeb.cornell.edu/agrawal/pdfs/1999/Cost-Evo-1999.pdf.

Basheer-Salimia, Rezq. 2007. "Juvenility, Maturation, and Rejuvenation in Woody Plants." Horticultural Reviews, no. September 2008: 109-55. https://doi.org/10.1002/2013GL058182.

Bellini, Elvio. 1993. "Variabilidad Genetica Heredabilidad de Algunos Caracteres En Plantas de Semillas de Olive Obtenidas Por Cruzamiento." Olivae: Revista Oficial Del Consejo Oleícola Internacional 49: 21-34.

Benjamini, Yoav, and Yosef Hochberg. 1995. "Controlling the False Discovery Rate: A Pratical and Powerful Approach to Multiple Testing." Journal of the Royal Statistical Society 57 (1): 289-300. http://www.math.tau.ac.il/ ybenja/MyPapers/benjamini_hochberg1995.pdf.

Bilichak, Andriy, and Igor Kovalchuk. 2016. "Transgenerational Response to Stress in Plants and Its Application for Breeding." Journal of Experimental Botany 67 (7): 2081-92. https://doi.org/10.1093/jxb/erw066.

Bond, Barbara J. 2000. "Age-Related Changes in Photosynthesis of Woody Plants." Trends in Plant Science 5 (8): 349-53. https://doi.org/10.1016/S1360-1385(00)01691-5.

Buels, Robert, Eric Yao, Colin M. Diesh, Richard D. Hayes, Monica Munoz-Torres, Gregg Helt, David M. Goodstein, et al. 2016. "JBrowse: A Dynamic Web Platform for Genome Visualization and Analysis." Genome Biology 17 (1): 66. https://doi.org/10.1186/s13059-016-0924-1.

Chan, Simon W.-L., lan R. Henderson, and Steven E. Jacobsen. 2005. "Gardening The Genome: DNA Methylation in Arabidopsis Thaliana." Nature Reviews Genetics 6 (7): 590-590. https://doi.org/10.1038/nrg1664.

Chedin, Frederic, Michael R Lieber, and Chih-Lin Hsieh. 2002. "The DNA Methyltransferaselike Protein DNMT3L Stimulates de Novo Methylation by Dnmt3a." Proceedings of the National Academy of Sciences of the United States of America 99 (26): 16916-21. https://doi.org/10.1073/pnas.262443999.

Choi, Yeonhee, Mary Gehring, Lianna Johnson, Mike Hannon, John J Harada, Robert B Goldberg, Steven E Jacobsen, Robert L Fischer, and Berkeley California. 2002. “DEMETER, a DNA Glycosylase Domain Protein, Is Required for Endosperm Gene Imprinting and Seed Viability in Arabidopsis Replicates to Form a Syncytium, and Following Cellulariza-Tion, Produces Storage Proteins, Lipids, and Starch." Cell. Vol. 110. http://www.sanger.ac.uk/Software/Pfam/.

Colicchio, Jack M, Fumihito Miura, John K Kelly, Takashi Ito, and Lena C Hileman. 2015. "DNA Methylation and Gene Expression in Mimulus Guttatus." BMC Genomics 16 (1). https://doi.org/10.1186/s12864-015-1668-0. 
Critchfield, William B. 1960. "LEAF DIMORPHISM IN POPULUS TRICHOCARPA." American Journal of Botany 47 (8): 699-711. https://doi.org/10.1002/j.1537-2197.1960.tb07154.x.

Daccord, Nicolas, Jean-Marc Celton, Gareth Linsmith, Claude Becker, Nathalie Choisne, Elio Schijlen, Henri van de Geest, et al. 2017. "High-Quality de Novo Assembly of the Apple Genome and Methylome Dynamics of Early Fruit Development." Nature Genetics. https://doi.org/10.1038/ng.3886.

Day, M. E., M. S. Greenwood, and C. Diaz-Sala. 2002. "Age- and Size-Related Trends in Woody Plant Shoot Development: Regulatory Pathways and Evidence for Genetic Control." Tree Physiology 22 (8): 507-13. https://doi.org/10.1093/treephys/22.8.507.

Depuydt, Stephen, Sandra Trenkamp, Alisdair R Fernie, Samira Elftieh, Jean-Pierre Renou, Marnik Vuylsteke, Marcelle Holsters, and Danny Vereecke. 2009. “An Integrated Genomics Approach to Define Niche Establishment by Rhodococcus Fascians 1[C][W][OA]." Plant Physiology 149: 1366-86. https://doi.org/10.1104/pp.108.131805.

“FAOSTAT." 2017. FOASTAT. 2017. http://www.fao.org/faostat/fr/\#data/QC.

Feng, Suhua, Steven E. Jacobsen, and Wolf Reik. 2010. "Epigenetic Reprogramming in Plant and Animal Development." Science 330 (6004): 622-27. https://doi.org/10.1126/science.1190614.Epigenetic.

Finnegan, E. J., R. K. Genger, W. J. Peacock, and E. S. Dennis. 1998. "DNA METHYLATION IN PLANTS." Annual Review of Plant Physiology and Plant Molecular Biology 49 (1): 223-47. https://doi.org/10.1146/annurev.arplant.49.1.223.

Greenwood, Michael S. 1984. "Phase Change in Loblolly Pine:Shoot Development as a Function of Age." Physiologia Plantarum 61 (3): 518-22. https://doi.org/10.1111/j.1399-3054.1984.tb06366.x.

Greenwood, Michael S. 1995. "Juvenility and Maturation in Conifers : Current Concepts," 433-38.

Gruenbaum, Yosef, Tally Naveh-Many, Howard Cedar, and Aharon Razin. 1981. "Sequence Specificity of Methylation in Higher Plant DNA." Nature 292 (5826): 860-62. https://doi.org/10.1038/292860a0.

Gutierrez-Marcos, J. F., and H. G. Dickinson. 2012. “Epigenetic Reprogramming in Plant Reproductive Lineages." Plant and Cell Physiology 53 (5): 817-23. https://doi.org/10.1093/pcp/pcs052.

Hackett, Wesley P., and John R. Murray. 2015. Maturation and Rejuvenation in Woody Plants. Acta Horticulturae. https://doi.org/10.17660/actahortic.1992.314.23.

Hagmann, J, C Becker, J Mü Ller, O Stegle, and R C Meyer. 2015. “Century-Scale Methylome Stability in a Recently Diverged Arabidopsis Thaliana Lineage." PLoS Genet 11 (1): 1004920. https://doi.org/10.1371/journal.pgen.1004920.

Han, Y Z, B Q Huang, S Y Zee, and M Yuan. 2000. "Symplastic Communication between the Central Cell and the Egg Apparatus Cells in the Embryo Sac of Torenia Fournieri Lind. 
before and during Fertilization." Planta 211 (1): 158-62. https://doi.org/10.1007/s004250000289.

Hand, P., R. T. Besford, C. M. Richardson, and S. D. Peppitt. 1996. "Antibodies to Phase Related Proteins in Juvenile and Mature Prunus Avium." Plant Growth Regulation 20 (1): 25-29. https://doi.org/10.1007/BF00024053.

Hanke, Magda-Viola, Henryk Flachowsky, Andreas Peil, and Conny Hättasch. 2007. "No Flower No Fruit-Genetic Potentials to Trigger Flowering in Fruit Trees." Genes Genomes Genomics 1 (1): 1-20.

Hauser, Marie Theres, Werner Aufsatz, Claudia Jonak, and Christian Luschnig. 2011. "Transgenerational Epigenetic Inheritance in Plants." Biochimica et Biophysica Acta Gene Regulatory Mechanisms. https://doi.org/10.1016/j.bbagrm.2011.03.007.

Herman, Jacob J, and Sonia E Sultan. 2011. "Adaptive Transgenerational Plasticity in Plants: Case Studies, Mechanisms, and Implications for Natural Populations." Frontiers in Plant Science 2: 102. https://doi.org/10.3389/fpls.2011.00102.

Herr, A. J., M B Jensen, T Dalmay, and D C Baulcombe. 2005. "RNA Polymerase IV Directs Silencing of Endogenous DNA." Science 308 (5718): 118-20. https://doi.org/10.1126/science.1106910.

Herrera, Carlos M., and Pilar Bazaga. 2013. “Epigenetic Correlates of Plant Phenotypic Plasticity: DNA Methylation Differs between Prickly and Nonprickly Leaves in Heterophyllous Ilex Aquifolium (Aquifoliaceae) Trees." Botanical Journal of the Linnean Society 171 (3): 441-52. https://doi.org/10.1111/boj.12007.

Herrera, Carlos M., Mónica Medrano, and Pilar Bazaga. 2016. “Comparative Spatial Genetics and Epigenetics of Plant Populations: Heuristic Value and a Proof of Concept." Molecular Ecology 25 (8): 1653-64. https://doi.org/10.1111/mec.13576.

Holliday, R, and J E Pugh. 1975. "DNA Modification Mechanisms and Gene Activity during Development." Source: Science, New Series 187 (4173): 226-32. http://www.jstor.org/stable/1739057.

Hutchison, Keith W., Christopher D. Sherman, Jill Weber, Sandra Schiller Smith, Patricia B. Singer, and Michael S. Greenwood. 1990. "Maturation in Larch: II. Effects of Age on Photosynthesis and Gene Expression in Developing Foliage." Plant Physiology 94 (3): 1308-15. http://www.jstor.org/stable/4273238.

Ibarra, Christian A, Xiaoqi Feng, Vera K Schoft, Tzung Fu Hsieh, Rie Uzawa, Jessica A Rodrigues, Assaf Zemach, et al. 2012. "Active DNA Demethylation in Plant Companion Cells Reinforces Transposon Methylation in Gametes." Science 337 (6100): 1360-64. https://doi.org/10.1126/science.1224839.

Ito, Hidetaka, Hervé Gaubert, Etienne Bucher, Marie Mirouze, Isabelle Vaillant, and Jerzy Paszkowski. 2011. "An SiRNA Pathway Prevents Transgenerational Retrotransposition in Plants Subjected to Stress." Nature 472 (7341): 115-19. https://doi.org/10.1038/nature09861. 
Jablonka, Eva, and Gal Raz. 2009. "Transgenerational Epigenetic Inheritance: Prevalence, Mechanisms, and Implications for the Study of Heredity and Evolution." The Quarterly Review of Biology 84 (2): 131-76. https://doi.org/10.1086/598822.

Jung, Sook, Taein Lee, Chun-Huai Cheng, Katheryn Buble, Ping Zheng, Jing Yu, Jodi Humann, et al. 2019. "15 Years of GDR: New Data and Functionality in the Genome Database for Rosaceae." Nucleic Acids Research 47 (D1): D1137-45. https://doi.org/10.1093/nar/gky1000.

Kanno, Tatsuo, Bruno Huettel, Florian Mette, Werner Aufsatz, Estelle Jaligot, Lucia Daxinger, David P Kreil, Marjori Matzke, and Antonius J M Matzke. 2005. "Atypical RNA Polymerase Subunits Required for RNA-Directed DNA Methylation." https://doi.org/10.1038/ng1580.

Kawashima, Tomokazu, and Frédéric Berger. 2014. "Epigenetic Reprogramming in Plant Sexual Reproduction." Nature Reviews Genetics 15 (9): 613-24. https://doi.org/10.1038/nrg3685.

Kim, M Yvonne, and Daniel Zilberman. 2014. "DNA Methylation as a System of Plant Genomic Immunity." Trends in Plant Science 19: 320-26. https://doi.org/10.1016/j.tplants.2014.01.014.

Köhler, Claudia, Philip Wolff, and Charles Spillane. 2012. "Epigenetic Mechanisms Underlying Genomic Imprinting in Plants." Annual Review of Plant Biology 63 (1): 331-52. https://doi.org/10.1146/annurev-arplant-042811-105514.

Lane, W. D. 1992. "Micropropagation of Apple (Malus Domestica Barkh.)." In , 229-43. Springer Berlin Heidelberg. https://doi.org/10.1007/978-3-642-76422-6_12.

Lavee, Shimon, N. Avidan, A. Haskal, and A. Ogrodovich. 1996. "Juvenility Period Reduction in Olive Seedlings-A Tool for Enhancement of Breeding." Olivae 60: 33-41.

Law, Julie A., and Steven E. Jacobsen. 2010. "Establishing, Maintaining and Modifying DNA Methylation Patterns in Plants and Animals." Nature Reviews Genetics 11 (3): 204-20. https://doi.org/10.1038/nrg2719.

Lespinasse, Yves, Lydie Bouvier, Mirsada Djulbic, and Elisabeth Chevreau. 1999. "Haploidy in Apple and Pear."

Li, Yan, Suresh Kumar, and Weiqiang Qian. 2018. "Active DNA Demethylation: Mechanism and Role in Plant Development." Plant Cell Reports 37: 77-85. https://doi.org/10.1007/s00299-017-2215-z.

Lindroth, A. M. 2001. "Requirement of CHROMOMETHYLASE3 for Maintenance of CpXpG Methylation." Science 292 (5524): 2077-80. https://doi.org/10.1126/science.1059745.

LOHSE, MARC, AXEL NAGEL, THOMAS HERTER, PATRICK MAY, MICHAEL SCHRODA, RITA ZRENNER, TAKAYUKI TOHGE, ALISDAIR R. FERNIE, MARK STITT, and BJÖRN USADEL. 2014. "Mercator: A Fast and Simple Web Server for Genome Scale Functional Annotation of Plant Sequence Data." Plant, Cell \& Environment 37 (5): 1250-58. https://doi.org/10.1111/pce.12231. 
Madlung, Andreas, and Luca Comai. 2004. "The Effect of Stress on Genome Regulation and Structure." Annals of Botany 94 (4): 481-95. https://doi.org/10.1093/aob/mch172.

Manning, Kenneth, Mahmut Tör, Mervin Poole, Yiguo Hong, Andrew J Thompson, Graham J King, James J Giovannoni, and Graham B Seymour. 2006. "A Naturally Occurring Epigenetic Mutation in a Gene Encoding an SBP-Box Transcription Factor Inhibits Tomato Fruit Ripening." Nature Genetics 38 (8): 948-52. https://doi.org/10.1038/ng1841.

McGowran, E., G. C. Douglas, and M. Parkinson. 1998. “Morphological and Physiological Markers of Juvenility and Maturity in Shoot Cultures of Oak (Quercus Robur and Q. Petraea)." Tree Physiology 18 (4): 251-57. https://doi.org/10.1093/treephys/18.4.251.

Medrano, Mõnica, Carlos M. Herrera, and Pilar Bazaga. 2014. "Epigenetic Variation Predicts Regional and Local Intraspecific Functional Diversity in a Perennial Herb." Molecular Ecology 23 (20): 4926-38. https://doi.org/10.1111/mec.12911.

Meilan, Richard. 1997. "Floral Induction in Woody Angiosperms." New Forests. Vol. 14. Kluwer Academic Publishers. https://link.springer.com/content/pdf/10.1023\%2FA\%3A1006560603966.pdf.

Meyer, Peter, Ingrid Niedenhof, and Michael Ten Lohuis. 1994. "Evidence for Cytosine Methylation of Non-Symmetrical Sequences in Transgenic Petunia Hybrida." The EMBO Journal. Vol. 13. https://www.ncbi.nlm.nih.gov/pmc/articles/PMC395059/pdf/emboj00057-0070.pdf.

Mirouze, Marie, and Jerzy Paszkowski. 2011. "Epigenetic Contribution to Stress Adaptation in Plants." Current Opinion in Plant Biology 14 (3): 267-74. https://doi.org/10.1016/j.pbi.2011.03.004.

Mirouze, Marie, Jon Reinders, Etienne Bucher, Taisuke Nishimura, Korbinian Schneeberger, Stephan Ossowski, Jun Cao, Detlef Weigel, Jerzy Paszkowski, and Olivier Mathieu. 2009. "Selective Epigenetic Control of Retrotransposition in Arabidopsis." Nature 461 (7262): 427-30. https://doi.org/10.1038/nature08328.

Miura, Asuka, Shoji Yonebayashi, Koichi Watanabe, T Toyama, H Shimada, and T Kakutani. 2001. "Mobilization of Transposons by a Mutation Abolishing Full DNA Methylation in Arabidopsis." Nature 411 (May): 212-14. https://doi.org/10.1038/35075612.

Murray, John R., Alan G. Smith, and Wesley P. Hackett. 1994. “Differential Dihydroflavonol Reductase Transcription and Anthocyanin Pigmentation in the Juvenile and Mature Phases of Ivy (Hedera Helix L.)." Planta 194 (1): 102-9. https://doi.org/10.1007/BF00201040.

Niederhuth, Chad E, Adam J Bewick, Lexiang Ji, Magdy Alabady, Kyung Do Kim, Justin T Page, Qing Li, et al. 2016. "Widespread Natural Variation of DNA Methylation within Angiosperms." BioRxiv, 1-19. https://doi.org/10.1101/045880.

Olmedo-Monfil, Vianey, Noé Durán-Figueroa, Mario Arteaga-Vandázquez, Edgar DemesaArévalo, Daphné Autran, Daniel Grimanelli, Keith Slotkin, Robert A Martienssen, and Jean-Philippe Vielle-Calzada. 2010. "Control of Female Gamete Formation by a Small 
RNA Pathway in Arabidopsis HHS Public Access." Nature 464 (7288): 628-32. https://doi.org/10.1038/nature08828.

Pfaffl, M W. 2001. "A New Mathematical Model for Relative Quantification in Real-Time RTPCR." Nucleic Acids Research 29 (9): e45. https://doi.org/10.1093/nar/29.9.e45.

Poethig, R Scott. 2003. "Phase Change and the Regulation of Developmental Timing in Plants." SCIENCE 301: 334-36. www.sciencemag.org.

Quadrana, Leandro, and Vincent Colot. 2016. "Plant Transgenerational Epigenetics." Annual Review of Genetics 50 (1): 467-91. https://doi.org/10.1146/annurev-genet-120215035254.

R Core Team. 2016. "R: A Language and Environment for Statistical Computing. R Foundation for Statistical Computing." Vienna, Austria.

Ramírez-Carrasco, Gabriela, Keren Martínez-Aguilar, and Raúl Alvarez-Venegas. 2017. "Transgenerational Defense Priming for Crop Protection against Plant Pathogens: A Hypothesis." Frontiers in Plant Science 8. https://doi.org/10.3389/fpls.2017.00696.

Rebbeck, Joanne, Keith F. Jensen, and Michael S. Greenwood. 1993. "Ozone Effects on Grafted Mature and Juvenile Red Spruce: Photosynthesis, Stomatal Conductance, and Chlorophyll Concentration." Canadian Journal of Forest Research 23 (3): 450-56. https://doi.org/10.1139/x93-063.

Rugini, E. 1986. “Olive (Olea Eu- Ropaea L.)." In Biotechnology in Agri- Culture and Forestry, Springer, 253-67.

Ryan, M.G., D. Binkley, and J.H. Fownes. 1997. "Age Related Decline in Forest Productivity: Pattern and Process." Advances in Ecological Research 27: 213-62.

Saze, Hidetoshi, Ortrun Mittelsten Scheid, and Jerzy Paszkowski. 2003. "Maintenance of CpG Methylation Is Essential for Epigenetic Inheritance during Plant Gametogenesis." Nature Genetics. https://doi.org/10.1038/ng1138.

Schermelleh, Lothar, Andrea Haemmer, Fabio Spada, Nicole Rö Sing, Daniela Meilinger, Ulrich Rothbauer, M Cristina Cardoso, and Heinrich Leonhardt. 2007. "Dynamics of Dnmt1 Interaction with the Replication Machinery and Its Role in Postreplicative Maintenance of DNA Methylation." Nucleic Acids Research 35 (13): 4301-12. https://doi.org/10.1093/nar/gkm432.

Schmitz, Robert J., Matthew D. Schultz, Mark A. Urich, Joseph R. Nery, Mattia Pelizzola, Ondrej Libiger, Andrew Alix, et al. 2013. "Patterns of Population Epigenomic Diversity." Nature. https://doi.org/10.1038/nature11968.

Schneider, Caroline A, Wayne S Rasband, and Kevin W Eliceiri. 2012. "NIH Image to ImageJ: 25 Years of Image Analysis." Nature Methods 9 (7): 671-75. https://doi.org/10.1038/NMETH.2089.

Slotkin, R Keith, Matthew Vaughn, Filipe Borges, Milos Tanurdzić, Jörg D Becker, José A Feijó, and Robert A Martienssen. 2009. "Epigenetic Reprogramming and Small RNA Silencing 
of Transposable Elements in Pollen." Cell 136 (3): 461-72. https://doi.org/10.1016/j.cell.2008.12.038.

Smyth, G. K., J. Michaud, and H. S. Scott. 2005. "Use of Within-Array Replicate Spots for Assessing Differential Expression in Microarray Experiments." Bioinformatics 21 (9): 2067-75. https://doi.org/10.1093/bioinformatics/bti270.

Song, Jie, Judith Irwin, and Caroline Dean. 2013. "Minireview Remembering the Prolonged Cold of Winter." Current Biology 23: 807-11. https://doi.org/10.1016/j.cub.2013.07.027.

Suzuki, Miho M, and Adrian Bird. 2008. "DNA Methylation Landscapes: Provocative Insights from Epigenomics." Nature Reviews. Genetics 9 (6): 465-76. https://doi.org/10.1038/nrg2341.

Telfer, Abby, Krista M. Bollman, and R. Scott Poethig. 1997. "Phase Change and the Regulation of Trichome Distribution in Arabidopsis Thaliana." Development 124: 645-54. https://dev.biologists.org/content/develop/124/3/645.full.pdf.

Untergasser, Andreas, Harm Nijveen, Xiangyu Rao, Ton Bisseling, René Geurts, and Jack A.M. Leunissen. 2007. "Primer3Plus, an Enhanced Web Interface to Primer3 Nucleic Acids." https://doi.org/10.1093/nar/gkm306.

Vandesompele, Jo, Katleen De Preter, Filip Pattyn, Bruce Poppe, Nadine Van Roy, Anne De Paepe, and Frank Speleman. 2002. "Accurate Normalization of Real-Time Quantitative RT-PCR Data by Geometric Averaging of Multiple Internal Control Genes." Genome Biology 3 (7): RESEARCH0034. https://doi.org/10.1186/gb-2002-3-7-research0034.

Verhoeven, Koen J F, and Veronica Preite. 2014. "Epigenetic Variation in Asexually Reproducing Organisms." Evolution 68 (3): 644-55. https://doi.org/10.1111/evo.12320.

Visser, T. 1964. "JUVENILE PHASE AND GROWTH OF APPLE AND PEAR SEEDLINGS." Euphytica. Vol. 13. https://link.springer.com/content/pdf/10.1007\%2FBF00033299.pdf.

Walker, James, Hongbo Gao, Jingyi Zhang, Billy Aldridge, Martin Vickers, James D. Higgins, and Xiaoqi Feng. 2018. "Sexual-Lineage-Specific DNA Methylation Regulates Meiosis in Arabidopsis." Nature Genetics 50 (1): 130-37. https://doi.org/10.1038/s41588-0170008-5.

Wang, Jia-Wei, Mee Yeon Park, Ling-Jian Wang, Yeonjong Koo, Xiao-Ya Chen, Detlef Weigel, and R. Scott Poethig. 2011. "MiRNA Control of Vegetative Phase Change in Trees." Edited by Ronald R. Sederoff. PLoS Genetics 7 (2): e1002012. https://doi.org/10.1371/journal.pgen.1002012.

Wassenegger, Michael, Sabine Heimes, Leonhard Riedel, and Heinz L. Sänger. 1994. "RNADirected de Novo Methylation of Genomic Sequences in Plants." Cell 76 (3): 567-76. https://doi.org/10.1016/0092-8674(94)90119-8.

Wilschut, Rutger A., Carla Oplaat, L. Basten Snoek, Jan Kirschner, and Koen J. F. Verhoeven. 2016. "Natural Epigenetic Variation Contributes to Heritable Flowering Divergence in a Widespread Asexual Dandelion Lineage." Molecular Ecology 25 (8): 1759-68. https://doi.org/10.1111/mec.13502. 
Xi, Yuanxin, and Wei Li. 2009. "BSMAP: Whole Genome Bisulfite Sequence MAPping Program." BMC Bioinformatics 10 (1): 232. https://doi.org/10.1186/1471-2105-10-232.

Zhang, Xiaoyu, Junshi Yazaki, Ambika Sundaresan, Shawn Cokus, Simon W L Chan, Huaming Chen, Ian R. Henderson, et al. 2006. "Genome-Wide High-Resolution Mapping and Functional Analysis of DNA Methylation in Arabidopsis." Cell 126 (6): 1189-1201. https://doi.org/10.1016/j.cell.2006.08.003.

Zhang, Xin Zhong, Yong Bo Zhao, Chun Min Li, Dong Mei Chen, Guang Peng Wang, Rui Feng Chang, and Huai Rui Shu. 2007. "Potential Polyphenol Markers of Phase Change in Apple (Malus Domestica)." Journal of Plant Physiology 164 (5): 574-80. https://doi.org/10.1016/j.jplph.2006.03.011.

Zilberman, Daniel, Mary Gehring, Robert K Tran, Tracy Ballinger, and Steven Henikoff. 2007. "Genome-Wide Analysis of Arabidopsis Thaliana DNA Methylation Uncovers an Interdependence between Methylation and Transcription." Nature Genetics 39 (1): 6169. https://doi.org/10.1038/ng1929.

Zimmerman, R.H. 1973. "JUVENILITY AND FLOWERING OF FRUIT TREES." In Acta Horticulturae 34: Symposium on Growth Regulators in Fruit Production, 139-42. Beltsville, Maryland, USA. https://doi.org/10.17660/ActaHortic.1973.34.17. 

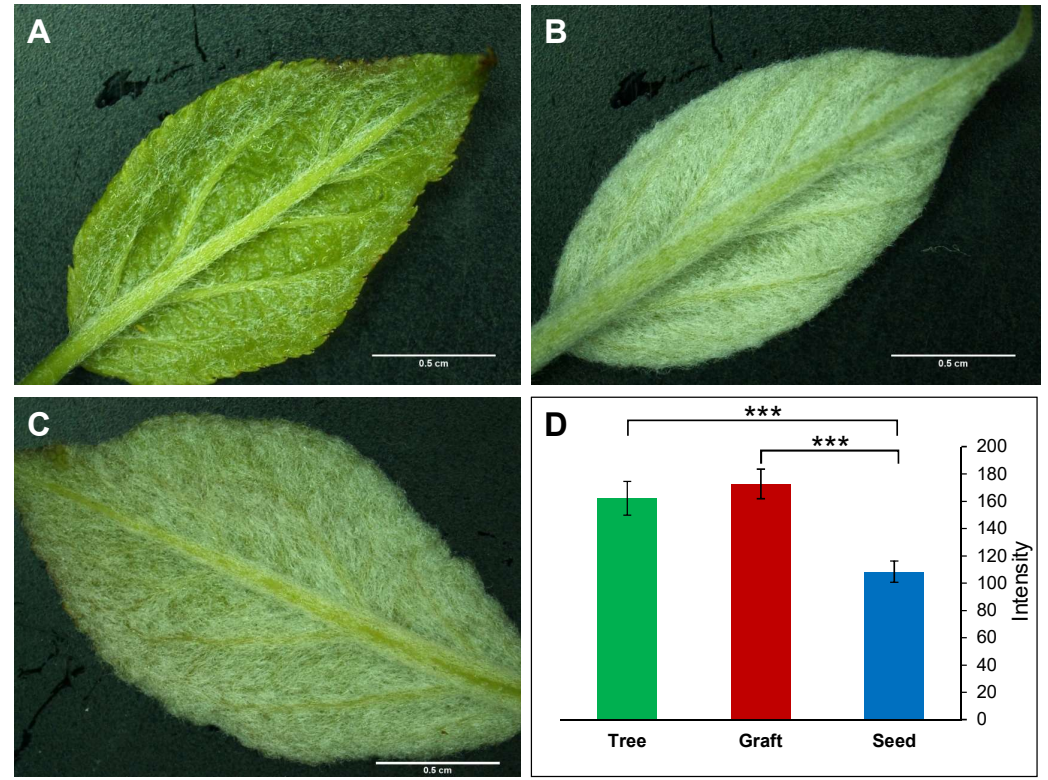

Figure 1: Leaf trichome density comparisons between seedlings, grafted plants and parental tree. Leaf pictures indicate visual differences in trichome density for seedlings $(A)$, grafts (B) and donor tree (C). The graph in (D), represents results from light intensity measurements carried out on the abaxial face of leaves. High light intensity correlates with high trichome density. $\mathrm{N}=60$ (5 measures on 12 leaves) per sample. Statistical differences were evaluated by a Kruskall-Wallis test two by two. Asterix p-value: ***: $1 \%$. 


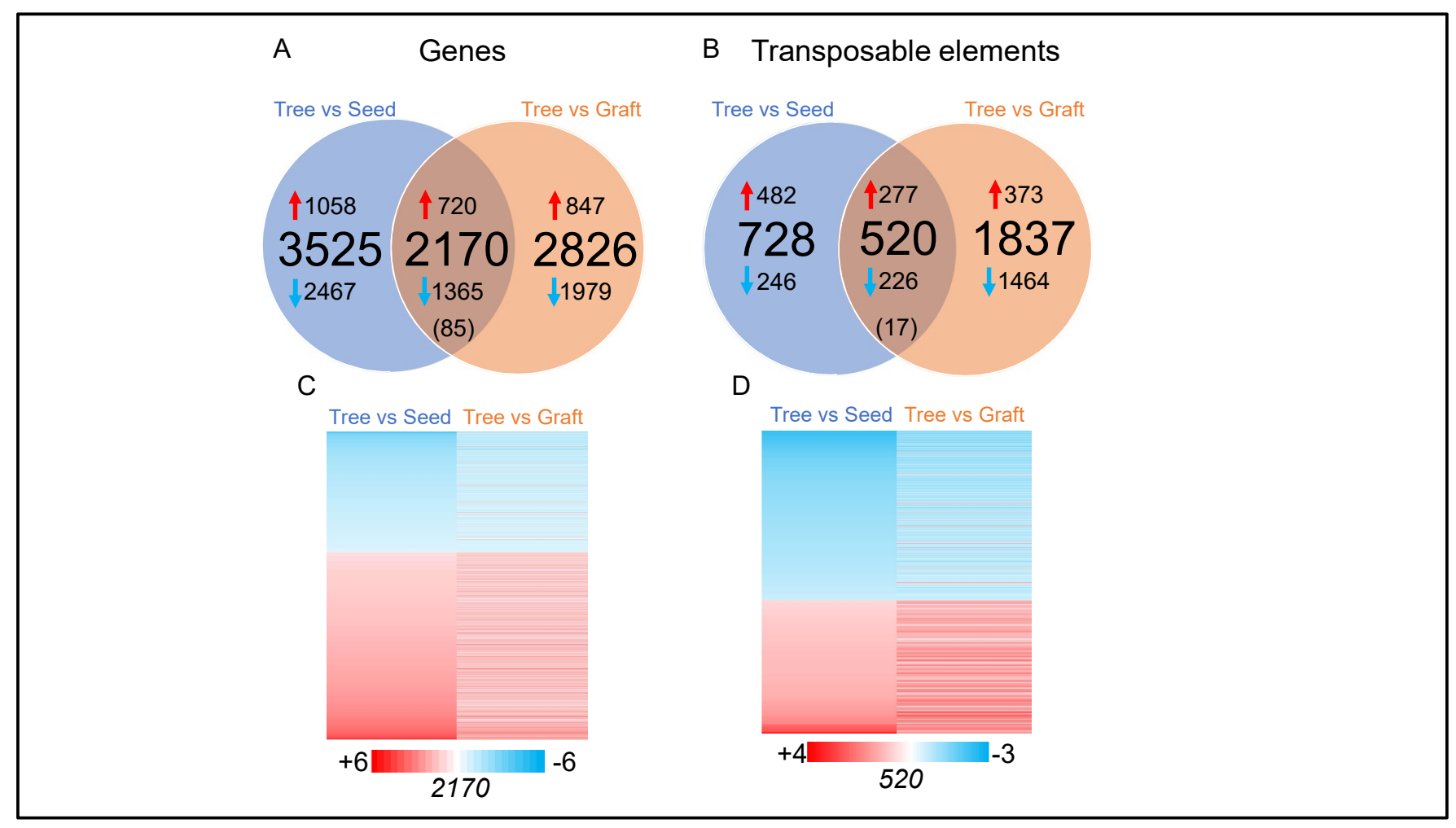

Figure 2: Transcriptome comparisons between seedling, grafts and donor tree.

Graphical representation of the number of differentially expressed transcripts in the different comparisons. (A) Venn diagram showing differentially transcribed genes (DEGs) in the comparisons TVS and TVG. (B) Venn diagram depicting differentially expressed TES (DETEs) in the comparisons TvS and TVG. The central number in brackets represent common DETs displaying alternative pattern of transcriptional regulation. In (C) and (D) the heat maps depict transcription ratios of common DEGs (C) and DETEs (D). Numbers of DETs in each heat map are indicated below it. Fold change ratios are shown in the color scale bar. 
A

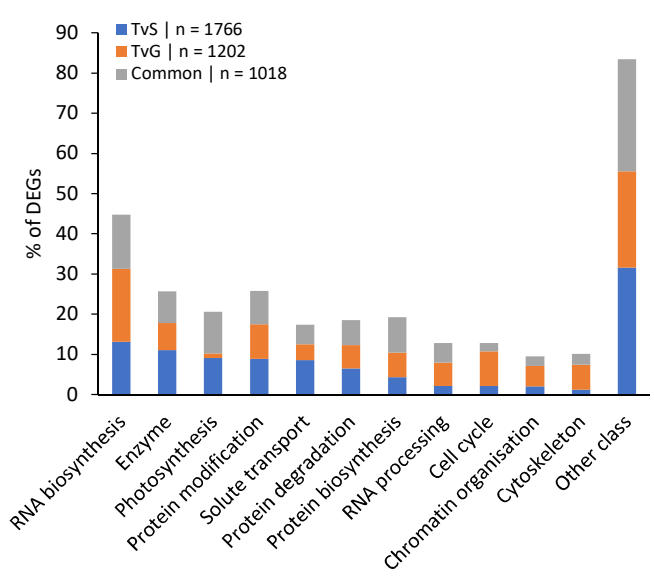

B

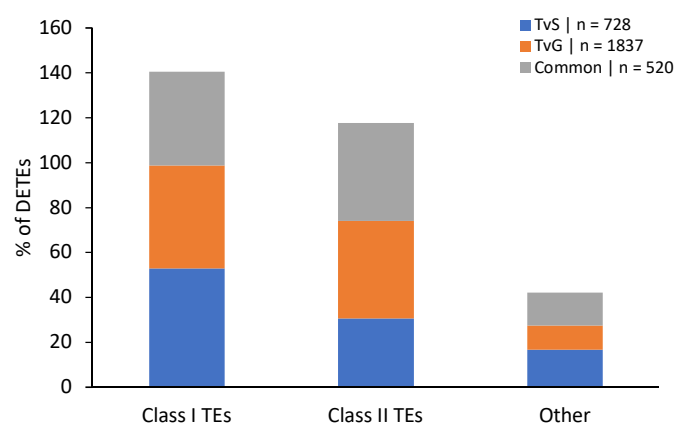

Figure 3: Classification of differentially expressed transcripts. (A) percentage of DEGs in each comparison in function of the gene classification according to Lohse et al. (2014). (B) percentage of DETEs in each comparison in function of TEs classification according to Daccord et al. (2018). Classes represented by less than $5 \%$ in the three condition were summed up in "Other class". 


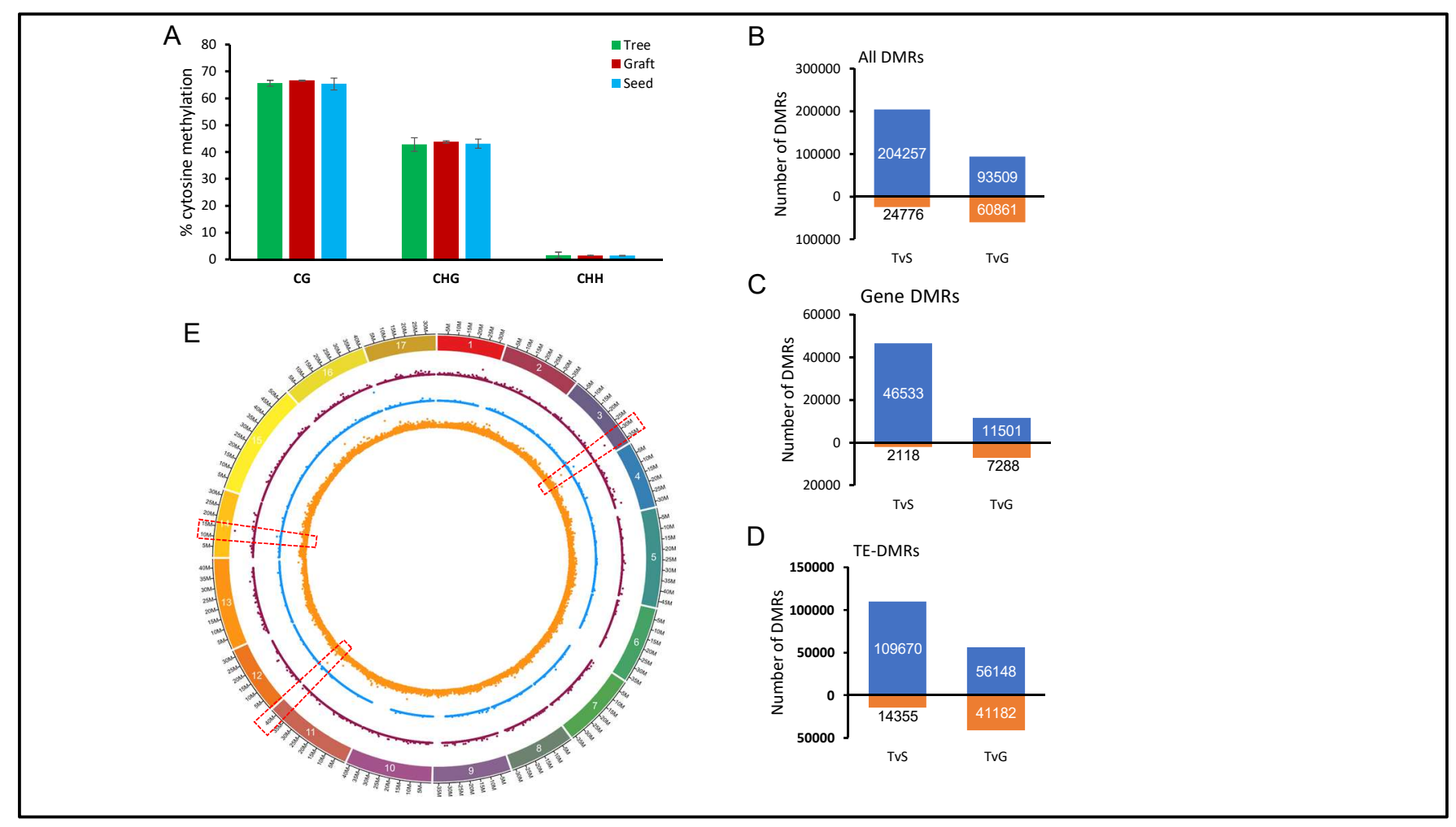

Figure 4: Global overview of DNA methylation differences between seedlings, grafts and trees. (A) Histogram presenting the genome wide cytosine methylation level (in percentage) of the three methylations context ( $\mathrm{CG}, \mathrm{CHG}$ and $\mathrm{CHH}$ ). Student test was performed to evaluate differences and the results ( $B, C$ and $D)$. Histograms representing the number of DMRs for each comparison: hypermethylated (above 0 , in blue) or hypomethylated (below 0, in orange) in the Tree samples for all DMRs (B), Gene-DMRs (C) and TE-DMRs (D). DMRs in all sequence contexts were counted and values are indicated in graph. (E) density plot of number of DMRs in $50 \mathrm{~kb}$ windows on the GDDH13 genome for TvS (see supplemental figure S1 for TvG). In red, DMRs in the CG context, in blue for the $\mathrm{CHG}$ context and in orange the $\mathrm{CHH}$ context. Each point represent the number of DMRs in a 50kb window of the genome. Red dashed boxes indicate the presence of DMR hot spots. 


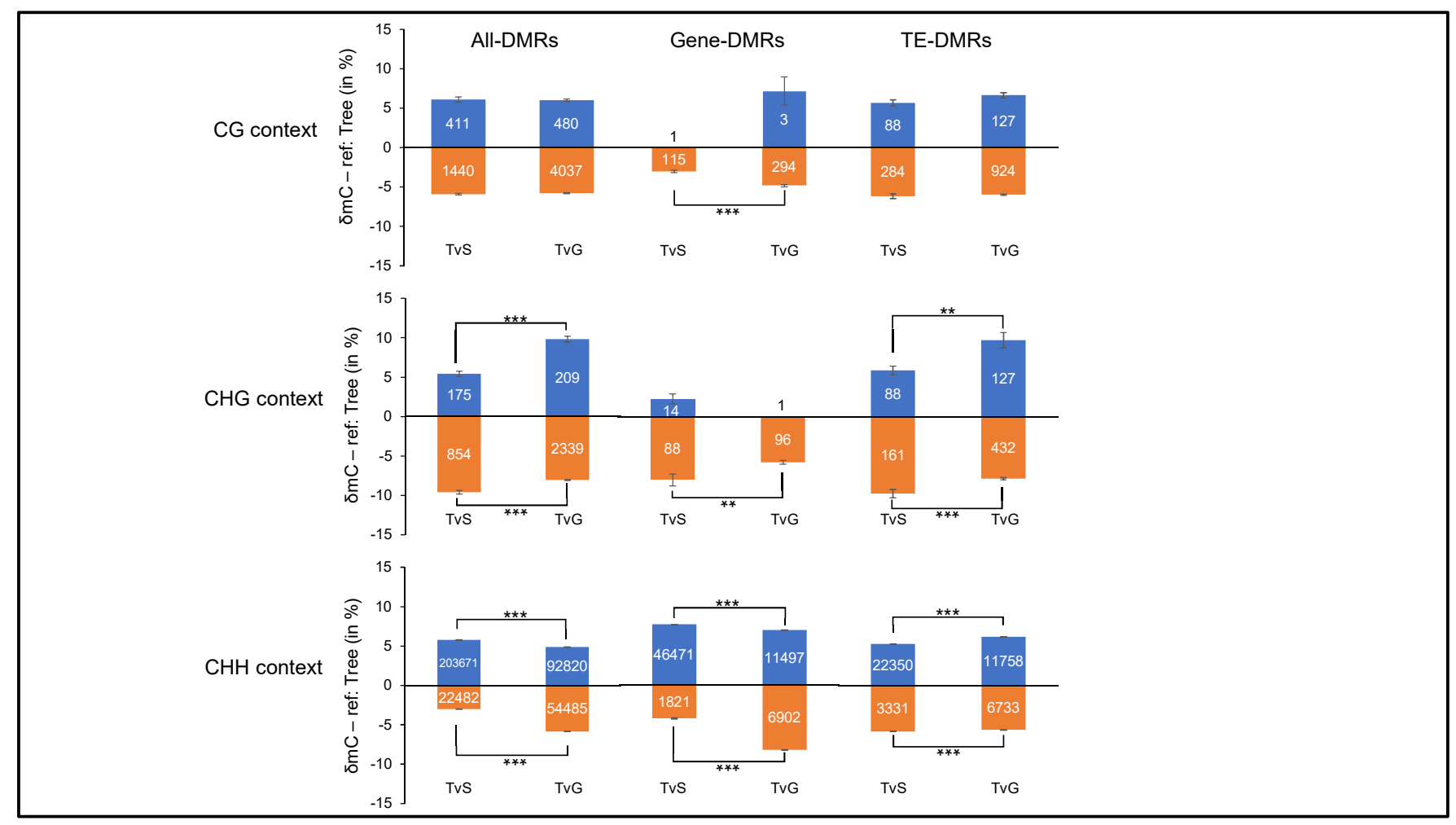

Figure 5: Levels of DNA methylation changes in gene and TE annotations. Histograms depicting DMR methylation variations $(\delta \mathrm{mC})$ between samples separated by sequence context and functional annotation. All DMRs are presented in the All-DMRs column, genes and TEs in the Gene-DMRs and TE-DMRs, respectively. DMRs were filtered by $p$ value and SDA (standard deviation average) in accordance to a fixed threshold (Table S2). Student test was performed to evaluate differences in $\delta \mathrm{mC}$, results are represented by an asterix depending on the $\mathrm{p}$-value threshold: ${ }^{*}: 5 \% ;{ }^{* *}: 1 \% ;{ }^{* * *}: 1 \%$. $\delta \mathrm{mC}$ : delta of methylation. The Tree sample was taken as reference to define the hyper- or hypomethylated state of DMRs. 


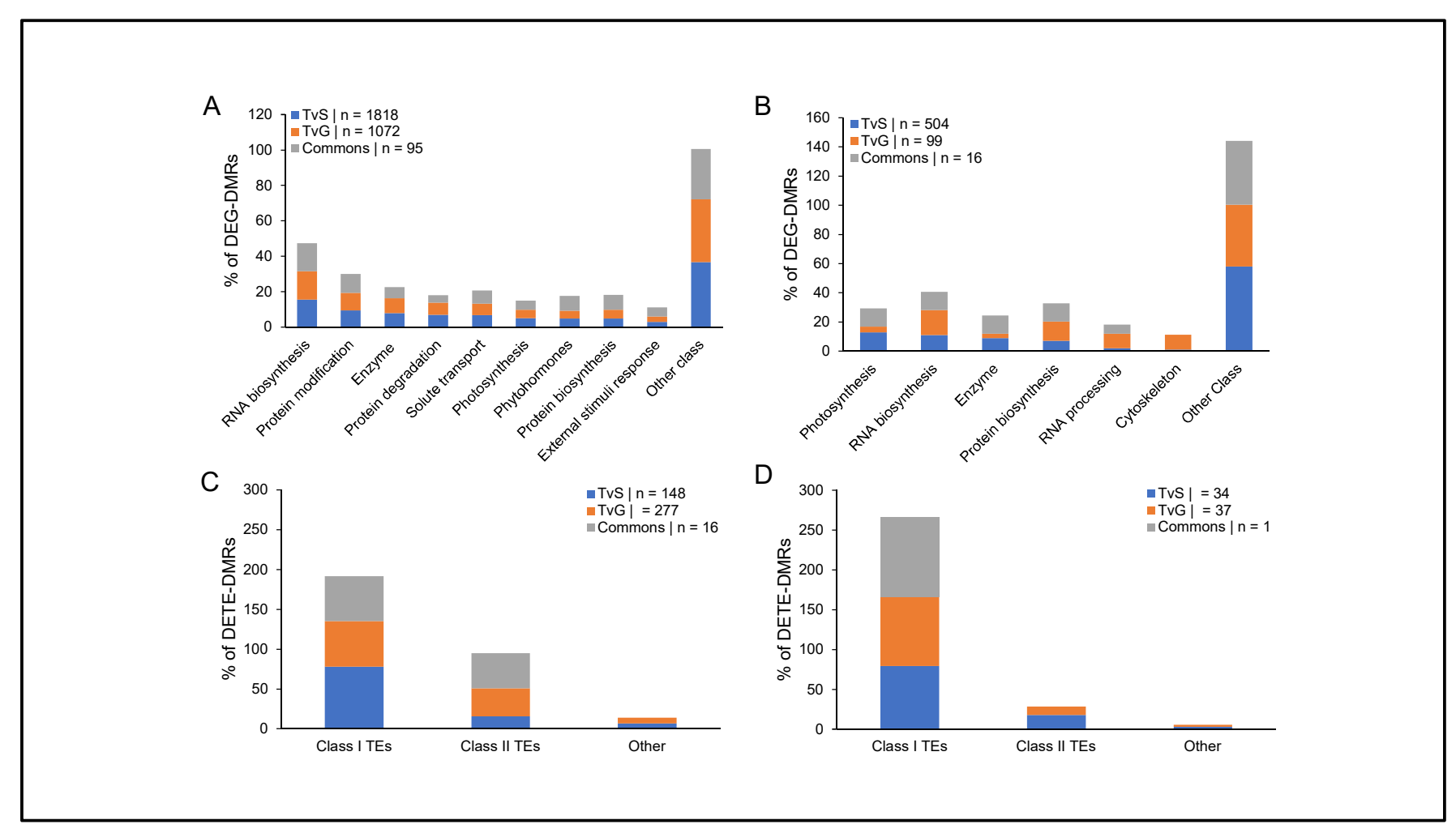

Figure 6: Classification of differentially expressed genes that are associated to DMRs. Histograms describing the percentage of DEG-DMRs (A and B) and DETE-DMRs (C and D) in the respective comparisons in function of gene or TEs classification. Only DMRs in the $\mathrm{CHH}$ context are presented here. In (A) and (C) all DEGs- and DETEs-DMRs were used while in (B) and (D) we only considered DEGs and DETEs with differential transcription ratio greater than 1.5 in absolute value. Gene classes representing less than $5 \%(A)$ or $10 \%$ (B) of the total in the three conditions were summed up in "other class". 


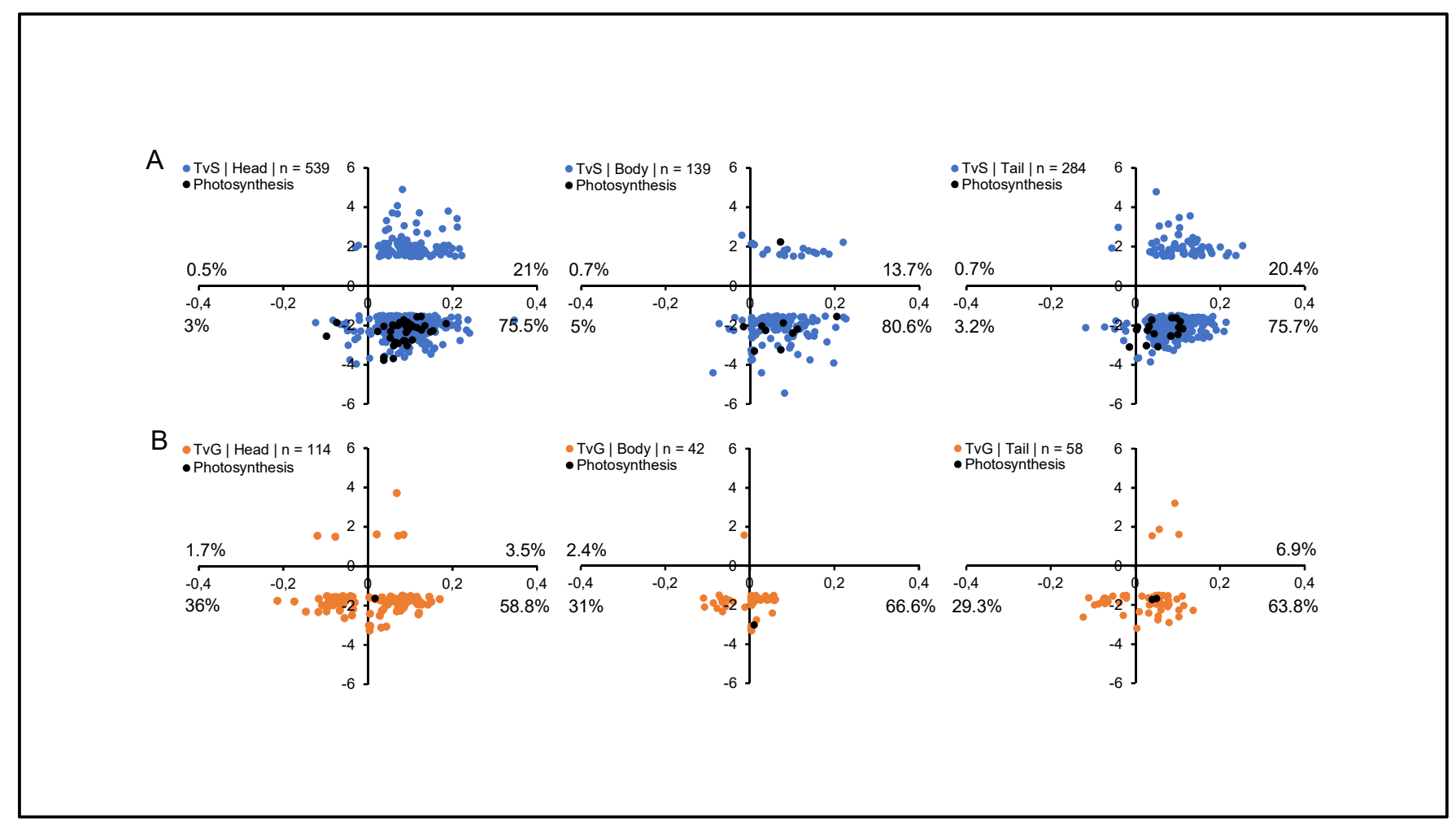

Figure 7 : Relationship between transcription ratio and DNA methylation variation Scatterplot representing DEG-DMRs in TVS (A) and TVG (B) in the CHH context, $\mathrm{X}$ axis represents $\delta \mathrm{mC}$ and $\mathrm{Y}$ axis represents gene expression ratios. In blue/orange are shown all DEG-DMRs and in black the ones specifically associated to photosynthesis. Numbers of DEG-DMRs used in each graph are indicated in the legend and corresponding percentages in each quadrant at the edges of the graph. We separated DEG-DMRs in function of the position of the DMRs related to the corrsponding gene (head = promoter, body, tail = terminator). 


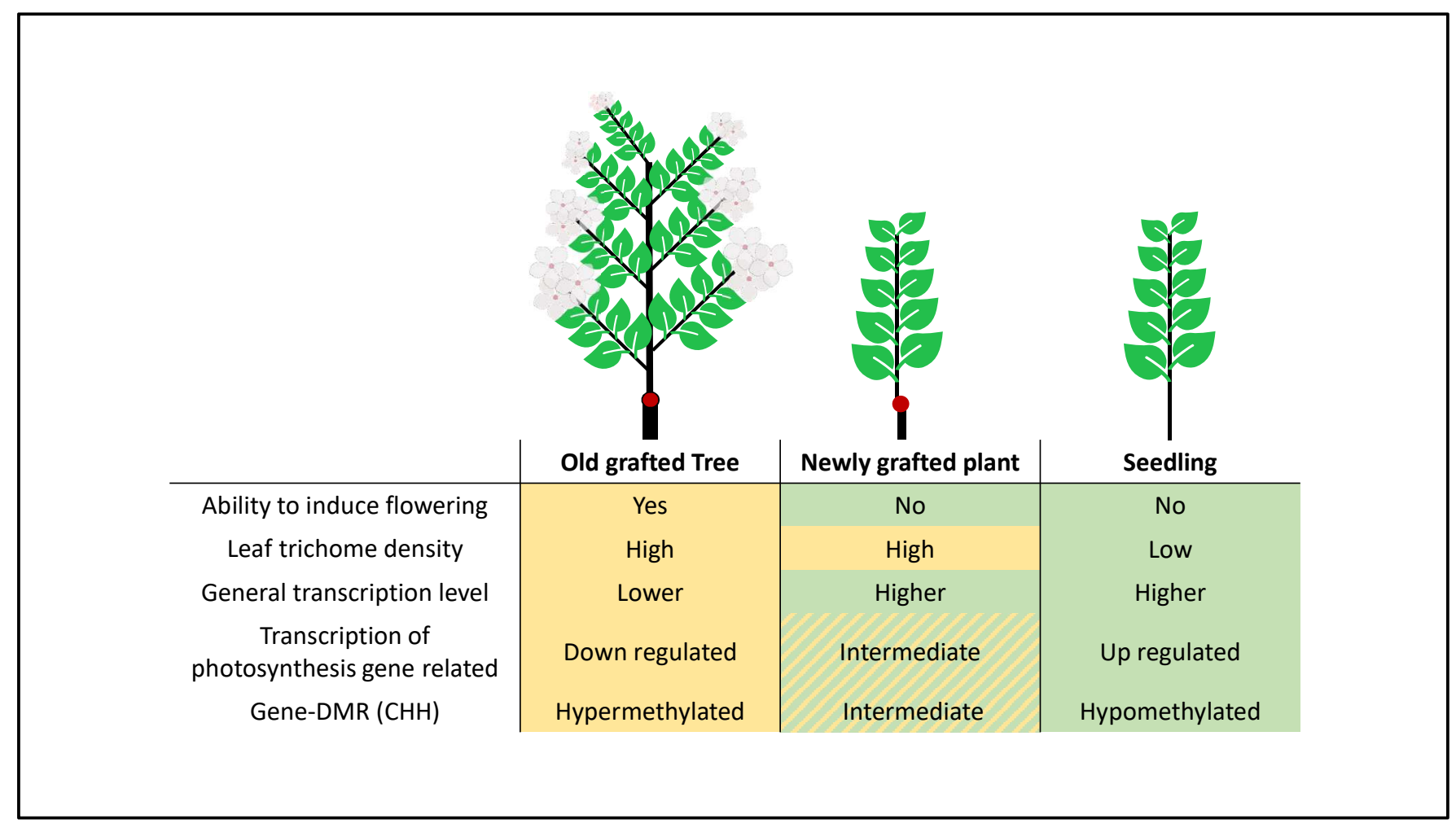

Figure 8: General overview of the main results of this study concerning physiological and molecular changes occurring during sexual and an asexual multiplication. The red dot represents the grafting point between scion and rootstock (larger line weight). Shared aspect between plants are highlighted by background colours. 


\section{Parsed Citations}

Agrawal, Anurag A, Sharon Y. Strauss, and Michael J. Stout. 1999. "Costs of Induced Responses and Tolerance to Herbivore in Male and Female Fitness Components of Wild Radish." Evolution. http://www.eeb.cornell.edu/agrawal/pdfs/1999/Cost-Evo-1999.pdf.

Pubmed: Author and Title

Google Scholar: Author Only Title Only Author and Title

Basheer-Salimia, Rezq. 2007. "Juvenility, Maturation, and Rejuvenation in Woody Plants." Horticultural Reviews, no. September 2008: 109-55. https://doi.org/10.1002/2013GL058182.

Pubmed: Author and Title

Google Scholar: Author Only Title Only Author and Title

Bellini, Elvio. 1993. "Variabilidad Genetica Heredabilidad de Algunos Caracteres En Plantas de Semillas de Olive Obtenidas Por Cruzamiento." Olivae: Revista Oficial Del Consejo Oleícola Internacional 49: 21-34.

Pubmed: Author and Title

Google Scholar: Author Only Title Only Author and Title

Benjamini, Yoav, and Yosef Hochberg. 1995. "Controlling the False Discovery Rate: APratical and Powerful Approach to Multiple Testing." Journal of the Royal Statistical Society 57 (1): 289-300.

http://www.math.tau.ac.il/ ybenja/MyPapers/benjamini_hochberg1995.pdf.

Pubmed: Author and Title

Google Scholar: Author Only Title Only Author and Title

Bilichak, Andriy, and Igor Kovalchuk. 2016. "Transgenerational Response to Stress in Plants and Its Application for Breeding." Journal of Experimental Botany 67 (7): 2081-92. https://doi.org/10.1093/jxb/erw066.

Pubmed: Author and Title

Google Scholar: Author Only Title Only Author and Title

Bond, Barbara J. 2000. "Age-Related Changes in Photosynthesis of Woody Plants." Trends in Plant Science 5 (8): 349-53.

https://doi.org/10.1016/S1360-1385(00)01691-5.

Pubmed: Author and Title

Google Scholar: Author Only Title Only Author and Title

Buels, Robert, Eric Yao, Colin M. Diesh, Richard D. Hayes, Monica Munoz-Torres, Gregg Helt, David M. Goodstein, et al. 2016.

"JBrowse: ADynamic Web Platform for Genome Visualization and Analysis." Genome Biology 17 (1): 66. https://doi.org/10.1186/s13059016-0924-1.

Pubmed: Author and Title

Google Scholar: Author Only Title Only Author and Title

Chan, Simon W.-L., lan R. Henderson, and Steven E. Jacobsen. 2005. "Gardening The Genome: DNA Methylation in Arabidopsis

Thaliana." Nature Reviews Genetics 6 (7): 590-590. https://doi.org/10.1038/nrg1664.

Pubmed: Author and Title

Google Scholar: Author Only Title Only Author and Title

Chedin, Frederic, Michael R Lieber, and Chih-Lin Hsieh. 2002. "The DNAMethyltransferase-like Protein DNMT3L Stimulates de Novo Methylation by Dnmt3a." Proceedings of the National Academy of Sciences of the United States of America 99 (26): 16916-21.

https://doi.org/10.1073/pnas.262443999.

Pubmed: Author and Title

Google Scholar: Author Only Title Only Author and Title

Choi, Yeonhee, Mary Gehring, Lianna Johnson, Mike Hannon, John J Harada, Robert B Goldberg, Steven E Jacobsen, Robert L Fischer, and Berkeley California. 2002. "DEMETER, a DNA Glycosylase Domain Protein, Is Required for Endosperm Gene Imprinting and Seed Viability in Arabidopsis Replicates to Form a Syncytium, and Following Cellulariza-Tion, Produces Storage Proteins, Lipids, and Starch." Cell. Vol. 110. http://www.sanger.ac.uk/Software/Pfaml.

Pubmed: Author and Title

Google Scholar: Author Only Title Only Author and Title

Colicchio, Jack M, Fumihito Miura, John K Kelly, Takashi Ito, and Lena C Hileman. 2015. "DNA Methylation and Gene Expression in Mimulus Guttatus." BMC Genomics 16 (1). https://doi.org/10.1186/s12864-015-1668-0.

Pubmed: Author and Title

Google Scholar: Author Only Title Only Author and Title

Critchfield, William B. 1960. "LEAF DIMORPHISM IN POPULUS TRICHOCARPA" American Journal of Botany 47 (8): 699-711. https://doi.org/10.1002/j.1537-2197.1960.tb07154.x.

Pubmed: Author and Title

Google Scholar: Author Only Title Only Author and Title

Daccord, Nicolas, Jean-Marc Celton, Gareth Linsmith, Claude Becker, Nathalie Choisne, Elio Schijlen, Henri van de Geest, et al. 2017. "High-Quality de Novo Assembly of the Apple Genome and Methylome Dynamics of Early Fruit Development." Nature Genetics. https://doi.org/10.1038/ng.3886.

Pubmed: Author and Title

Google Scholar: Author Only Title Only Author and Title 
Day, M. E., M. S. Greenwood, and C. Diaz-Sala. 2002. "Age- and Size-Related Trends in Woody Plant Shoot Development: Regulatory

Pathways and Evidence for Genetic Control." Tree Physiology 22 (8): 507-13. https://doi.org/10.1093/treephys/22.8.507.

Pubmed: Author and Title

Google Scholar: Author Only Title Only Author and Title

Depuydt, Stephen, Sandra Trenkamp, Aisdair R Fernie, Samira Elftieh, Jean-Pierre Renou, Marnik Vuylsteke, Marcelle Holsters, and Danny Vereecke. 2009. "An Integrated Genomics Approach to Define Niche Establishment by Rhodococcus Fascians 1[C][W][OA]."

Plant Physiology 149: 1366-86. https://doi.org/10.1104/pp.108.131805.

Pubmed: Author and Title

Google Scholar: Author Only Title Only Author and Title

"FAOSTAT." 2017. FOASTAT. 2017. http://uww.fao.org/faostat/fr/\#data/QC.

Pubmed: Author and Title

Google Scholar: Author Only Title Only Author and Title

Feng, Suhua, Steven E. Jacobsen, and Wolf Reik. 2010. "Epigenetic Reprogramming in Plant and Animal Development." Science 330 (6004): 622-27. https://doi.org/10.1126/science.1190614.Epigenetic.

Pubmed: Author and Title

Google Scholar: Author Only Title Only Author and Title

Finnegan, E. J., R. K. Genger, W. J. Peacock, and E. S. Dennis. 1998. "DNAMETHYLATION IN PLANTS." Annual Review of Plant Physiology and Plant Molecular Biology 49 (1): 223-47. https://doi.org/10.1146/annurev.arplant.49.1.223.

Pubmed: Author and Title

Google Scholar: Author Only Title Only Author and Title

Greenwood, Michael S. 1984. "Phase Change in Loblolly Pine:Shoot Development as a Function of Age." Physiologia Plantarum 61 (3): 518-22. https://doi.org/10.1111/j.1399-3054.1984.tb06366.x.

Pubmed: Author and Title

Google Scholar: Author Only Title Only Author and Title

Greenwood, Michael S. 1995. "Juvenility and Maturation in Conifers : Current Concepts," 433-38.

Pubmed: Author and Title

Google Scholar: Author Only Title Only Author and Title

Gruenbaum, Yosef, Tally Naveh-Many, Howard Cedar, and Aharon Razin. 1981. "Sequence Specificity of Methylation in Higher Plant DNA" Nature 292 (5826): 860-62. https://doi.org/10.1038/292860a0.

Pubmed: Author and Title

Google Scholar: Author Only Title Only Author and Title

Gutierrez-Marcos, J. F., and H. G. Dickinson. 2012. "Epigenetic Reprogramming in Plant Reproductive Lineages." Plant and Cell

Physiology 53 (5): 817-23. https://doi.org/10.1093/pcp/pcs052.

Pubmed: Author and Title

Google Scholar: Author Only Title Only Author and Title

Hackett, Wesley P., and John R. Murray. 2015. Maturation and Rejuvenation in Woody Plants. Acta Horticulturae.

https://doi.org/10.17660/actahortic.1992.314.23.

Pubmed: Author and Title

Google Scholar: Author Only Title Only Author and Title

Hagmann, J, C Becker, J Mü Ller, O Stegle, and R C Meyer. 2015. "Century-Scale Methylome Stability in a Recently Diverged Arabidopsis Thaliana Lineage." PLoS Genet 11 (1): 1004920. https://doi.org/10.1371/journal.pgen.1004920.

Pubmed: Author and Title

Google Scholar: Author Only Title Only Author and Title

Han, Y Z, B Q Huang, S Y Zee, and M Yuan. 2000. "Symplastic Communication between the Central Cell and the Egg Apparatus Cells in the Embryo Sac of Torenia Fournieri Lind. before and during Fertilization." Planta 211 (1): $158-62$.

https://doi.org/10.1007/s004250000289.

Pubmed: Author and Title

Google Scholar: Author Only Title Only Author and Title

Hand, P., R. T. Besford, C. M. Richardson, and S. D. Peppitt. 1996. "Antibodies to Phase Related Proteins in Juvenile and Mature

Prunus Avium" Plant Growth Regulation 20 (1): 25-29. https://doi.org/10.1007/BF00024053.

Pubmed: Author and Title

Google Scholar: Author Only Title Only Author and Title

Hanke, Magda-Viola, Henryk Flachowsky, Andreas Peil, and Conny Hättasch. 2007. "No Flower No Fruit-Genetic Potentials to Trigger Flowering in Fruit Trees." Genes Genomes Genomics 1 (1): 1-20.

Pubmed: Author and Title

Google Scholar: Author Only Title Only Author and Title

Hauser, Marie Theres, Werner Aufsatz, Claudia Jonak, and Christian Luschnig. 2011. "Transgenerational Epigenetic Inheritance in Plants." Biochimica et Biophysica Acta - Gene Regulatory Mechanisms. https://doi.org/10.1016/j.bbagrm2011.03.007.

Pubmed: Author and Title

Google Scholar: Author Only Title Only Author and Title 
Herman, Jacob J, and Sonia E Sultan. 2011. "Adaptive Transgenerational Plasticity in Plants: Case Studies, Mechanisms, and Implications for Natural Populations." Frontiers in Plant Science 2: 102. https://doi.org/10.3389/fpls.2011.00102.

Pubmed: Author and Title

Google Scholar: Author Only Title Only Author and Title

Herr, A J., M B Jensen, T Dalmay, and D C Baulcombe. 2005. "RNAPolymerase IV Directs Silencing of Endogenous DNA" Science 308 (5718): 118-20. https://doi.org/10.1126/science.1106910.

Pubmed: Author and Title

Google Scholar: Author Only Title Only Author and Title

Herrera, Carlos M., and Pilar Bazaga. 2013. "Epigenetic Correlates of Plant Phenotypic Plasticity: DNAMethylation Differs between Prickly and Nonprickly Leaves in Heterophyllous llex Aquifolium(Aquifoliaceae) Trees." Botanical Journal of the Linnean Society 171 (3): 441-52. https://doi.org/10.1111/boj.12007.

Pubmed: Author and Title

Google Scholar: Author Only Title Only Author and Title

Herrera, Carlos M., Mónica Medrano, and Pilar Bazaga. 2016. "Comparative Spatial Genetics and Epigenetics of Plant Populations: Heuristic Value and a Proof of Concept." Molecular Ecology 25 (8): 1653-64. https://doi.org/10.1111/mec.13576.

Pubmed: Author and Title

Google Scholar: Author Only Title Only Author and Title

Holliday, R, and J E Pugh. 1975. "DNA Modification Mechanisms and Gene Activity during Development." Source: Science, New Series 187 (4173): 226-32. http://uww.jstor.org/stable/1739057.

Pubmed: Author and Title

Google Scholar: Author Only Title Only Author and Title

Hutchison, Keith W., Christopher D. Sherman, Jill Weber, Sandra Schiller Smith, Patricia B. Singer, and Michael S. Greenwood. 1990.

"Maturation in Larch: Il. Effects of Age on Photosynthesis and Gene Expression in Developing Foliage." Plant Physiology 94 (3): 1308-

15. http://www.jstor.org/stable/4273238.

Pubmed: Author and Title

Google Scholar: Author Only Title Only Author and Title

Ibarra, Christian A, Xiaoqi Feng, Vera K Schoft, Tzung Fu Hsieh, Rie Uzawa, Jessica ARodrigues, Assaf Zemach, et al. 2012. "Active DNADemethylation in Plant Companion Cells Reinforces Transposon Methylation in Gametes." Science 337 (6100): $1360-64$.

https://doi.org/10.1126/science.1224839.

Pubmed: Author and Title

Google Scholar: Author Only Title Only Author and Title

Ito, Hidetaka, Hervé Gaubert, Etienne Bucher, Marie Mirouze, Isabelle Vaillant, and Jerzy Paszkowski. 2011. "An SiRNAPathway Prevents Transgenerational Retrotransposition in Plants Subjected to Stress." Nature 472 (7341): 115-19.

https://doi.org/10.1038/nature09861.

Pubmed: Author and Title

Google Scholar: Author Only Title Only Author and Title

Jablonka, Eva, and Gal Raz. 2009. "Transgenerational Epigenetic Inheritance: Prevalence, Mechanisms, and Implications for the Study of Heredity and Evolution." The Quarterly Review of Biology 84 (2): 131-76. https://doi.org/10.1086/598822.

Pubmed: Author and Title

Google Scholar: Author Only Title Only Author and Title

Jung, Sook, Taein Lee, Chun-Huai Cheng, Katheryn Buble, Ping Zheng, Jing Yu, Jodi Humann, et al. 2019. "15 Years of GDR: New Data and Functionality in the Genome Database for Rosaceae." Nucleic Acids Research 47 (D1): D1137-45.

https://doi.org/10.1093/nar/gky1000.

Pubmed: Author and Title

Google Scholar: Author Only Title Only Author and Title

Kanno, Tatsuo, Bruno Huettel, Florian Mette, Werner Aufsatz, Estelle Jaligot, Lucia Daxinger, David P Kreil, Marjori Matzke, and Antonius J M Matzke. 2005. "Atypical RNAPolymerase Subunits Required for RNA-Directed DNAMethylation."

https://doi.org/10.1038/ng1580.

Pubmed: Author and Title

Google Scholar: Author Only Title Only Author and Title

Kawashima, Tomokazu, and Frédéric Berger. 2014. "Epigenetic Reprogramming in Plant Sexual Reproduction." Nature Reviews Genetics 15 (9): 613-24. https://doi.org/10.1038/nrg3685.

Pubmed: Author and Title

Google Scholar: Author Only Title Only Author and Title

Kim, M Yvonne, and Daniel Zlberman. 2014. "DNA Methylation as a System of Plant Genomic Immunity." Trends in Plant Science 19: 320-26. https://doi.org/10.1016/j.tplants.2014.01.014.

Pubmed: Author and Title

Google Scholar: Author Only Title Only Author and Title

Köhler, Claudia, Philip Wolff, and Charles Spillane. 2012. "Epigenetic Mechanisms Underlying Genomic Imprinting in Plants." Annual Review of Plant Biology 63 (1): 331-52. https://doi.org/10.1146/annurev-arplant-042811-105514.

Pubmed: Author and Title 
Lane, W. D. 1992. "Micropropagation of Apple (Malus Domestica Barkh.)." In , 229-43. Springer Berlin Heidelberg.

https://doi.org/10.1007/978-3-642-76422-6_12.

Pubmed: Author and Title

Google Scholar: Author Only Title Only Author and Title

Lavee, Shimon, N. Avidan, A Haskal, and A Ogrodovich. 1996. "Juvenility Period Reduction in Olive Seedlings-A Tool for

Enhancement of Breeding." Olivae 60: 33-41.

Pubmed: Author and Title

Google Scholar: Author Only Title Only Author and Title

Law, Julie A, and Steven E. Jacobsen. 2010. "Establishing, Maintaining and Modifying DNA Methylation Patterns in Plants and

Animals." Nature Reviews Genetics 11 (3): 204-20. https://doi.org/10.1038/nrg2719.

Pubmed: Author and Title

Google Scholar: Author Only Title Only Author and Title

Lespinasse, Yves, Lydie Bouvier, Mirsada Djulbic, and Elisabeth Chevreau. 1999. "Haploidy in Apple and Pear.”

Li, Yan, Suresh Kumar, and Weiqiang Qian. 2018. "Active DNADemethylation: Mechanismand Role in Plant Development." Plant Cell Reports 37: 77-85. https://doi.org/10.1007/s00299-017-2215-z.

Pubmed: Author and Title

Google Scholar: Author Only Title Only Author and Title

Lindroth, A M. 2001. "Requirement of CHROMOMETHYLASE3 for Maintenance of CpXpG Methylation." Science 292 (5524): $2077-80$. https://doi.org/10.1126/science.1059745.

Pubmed: Author and Title

Google Scholar: Author Only Title Only Author and Title

LOHSE, MARC, AXEL NAGEL, THOMAS HERTER, PATRICK MAY, MICHAEL SCHRODA, RITAZRENNER, TAKAYUKI TOHGE, ALISDAR

R. FERNIE, MARK STITT, and BJÖRN USADEL. 2014. "Mercator: AFast and Simple Web Server for Genome Scale Functional

Annotation of Plant Sequence Data." Plant, Cell \& Environment 37 (5): 1250-58. https://doi.org/10.1111/pce.12231.

Pubmed: Author and Title

Google Scholar: Author Only Title Only Author and Title

Madlung, Andreas, and Luca Comai. 2004. "The Effect of Stress on Genome Regulation and Structure." Annals of Botany 94 (4): $481-95$. https://doi.org/10.1093/aob/mch172.

Pubmed: Author and Title

Google Scholar: Author Only Title Only Author and Title

Manning, Kenneth, Mahmut Tör, Mervin Poole, Yiguo Hong, Andrew J Thompson, Graham J King, James J Giovannoni, and Graham B Seymour. 2006. "ANaturally Occurring Epigenetic Mutation in a Gene Encoding an SBP-Box Transcription Factor Inhibits Tomato Fruit Ripening." Nature Genetics 38 (8): 948-52. https://doi.org/10.1038/ng1841.

Pubmed: Author and Title

Google Scholar: Author Only Title Only Author and Title

McGowran, E., G. C. Douglas, and M. Parkinson. 1998. "Morphological and Physiological Markers of Juvenility and Maturity in Shoot Cultures of Oak (Quercus Robur and Q. Petraea)." Tree Physiology 18 (4): 251-57. https://doi.org/10.1093/treephys/18.4.251.

Pubmed: Author and Title

Google Scholar: Author Only Title Only Author and Title

Medrano, Mõnica, Carlos M. Herrera, and Pilar Bazaga. 2014. "Epigenetic Variation Predicts Regional and Local Intraspecific

Functional Diversity in a Perennial Herb." Molecular Ecology 23 (20): 4926-38. https://doi.org/10.1111/mec.12911.

Pubmed: Author and Title

Google Scholar: Author Only Title Only Author and Title

Meilan, Richard. 1997. "Floral Induction in Woody Angiosperms." New Forests. Vol. 14. Kluwer Academic Publishers.

https://link.springer.com/content/pdf/10.1023\%2FA\%3A1006560603966.pdf.

Pubmed: Author and Title

Google Scholar: Author Only Title Only Author and Title

Meyer, Peter, Ingrid Niedenhof, and Michael Ten Lohuis. 1994. "Evidence for Cytosine Methylation of Non-Symmetrical Sequences in Transgenic Petunia Hybrida." The EMBO Journal. Vol. 13. https://uww.ncbi.nlm.nih.gov/pmc/articles/PMC395059/pdf/emboj000570070.pdf.

Pubmed: Author and Title

Google Scholar: Author Only Title Only Author and Title

Mirouze, Marie, and Jerzy Paszkowski. 2011. "Epigenetic Contribution to Stress Adaptation in Plants." Current Opinion in Plant Biology 14 (3): 267-74. https://doi.org/10.1016/j.pbi.2011.03.004.

Pubmed: Author and Title

Google Scholar: Author Only Title Only Author and Title

Mirouze, Marie, Jon Reinders, Etienne Bucher, Taisuke Nishimura, Korbinian Schneeberger, Stephan Ossowski, Jun Cao, Detlef Weigel, Jerzy Paszkowski, and Olivier Mathieu. 2009. "Selective Epigenetic Control of Retrotransposition in Arabidopsis." Nature 461 (7262): 427-30. https://doi.org/10.1038/nature08328. 
Miura, Asuka, Shoji Yonebayashi, Koichi Watanabe, T Toyama, H Shimada, and T Kakutani. 2001. "Mobilization of Transposons by a Mutation Abolishing Full DNA Methylation in Arabidopsis." Nature 411 (May): 212-14. https://doi.org/10.1038/35075612.

Pubmed: Author and Title

Google Scholar: Author Only Title Only Author and Title

Murray, John R., Alan G. Smith, and Wesley P. Hackett. 1994. "Differential Dihydroflavonol Reductase Transcription and Anthocyanin Pigmentation in the Juvenile and Mature Phases of Ivy (Hedera Helix L.)." Planta 194 (1): 102-9. https://doi.org/10.1007/BF00201040.

Pubmed: Author and Title

Google Scholar: Author Only Title Only Author and Title

Niederhuth, Chad E, Adam J Bewick, Lexiang Ji, Magdy Alabady, Kyung Do Kim, Justin T Page, Qing Li, et al. 2016. "Widespread Natural Variation of DNAMethylation within Angiosperms." BioRxiv, 1-19. https://doi.org/10.1101/045880.

Pubmed: Author and Title

Google Scholar: Author Only Title Only Author and Title

Olmedo-Monfil, Vianey, Noé Durán-Figueroa, Mario Arteaga-Vandázquez, Edgar Demesa-Arévalo, Daphné Autran, Daniel Grimanelli, Keith Slotkin, Robert A Martienssen, and Jean-Philippe Vielle-Calzada. 2010. "Control of Female Gamete Formation by a Small RNA Pathway in Arabidopsis HHS Public Access." Nature 464 (7288): 628-32. https://doi.org/10.1038/nature08828.

Pubmed: Author and Title

Google Scholar: Author Only Title Only Author and Title

Pfaffl, M W. 2001. "ANew Mathematical Model for Relative Quantification in Real-Time RT-PCR." Nucleic Acids Research 29 (9): e45. https://doi.org/10.1093/nar/29.9.e45.

Pubmed: Author and Title

Google Scholar: Author Only Title Only Author and Title

Poethig, R Scott. 2003. "Phase Change and the Regulation of Developmental Timing in Plants." SCIENCE 301: $334-36$.

www.sciencemag.org.

Pubmed: Author and Title

Google Scholar: Author Only Title Only Author and Title

Quadrana, Leandro, and Vincent Colot. 2016. "Plant Transgenerational Epigenetics." Annual Review of Genetics 50 (1): $467-91$. https://doi.org/10.1146/annurev-genet-120215-035254.

Pubmed: Author and Title

Google Scholar: Author Only Title Only Author and Title

R Core Team 2016. "R: A Language and Environment for Statistical Computing. R Foundation for Statistical Computing." Vienna, Austria.

Pubmed: Author and Title

Google Scholar: Author Only Title Only Author and Title

Ramírez-Carrasco, Gabriela, Keren Martínez-Aguilar, and Raúl Alvarez-Venegas. 2017. "Transgenerational Defense Priming for Crop Protection against Plant Pathogens: AHypothesis." Frontiers in Plant Science 8. https://doi.org/10.3389/fpls.2017.00696.

Pubmed: Author and Title

Google Scholar: Author Only Title Only Author and Title

Rebbeck, Joanne, Keith F. Jensen, and Michael S. Greenwood. 1993. "Ozone Effects on Grafted Mature and Juvenile Red Spruce: Photosynthesis, Stomatal Conductance, and Chlorophyll Concentration." Canadian Journal of Forest Research 23 (3): $450-56$. https://doi.org/10.1139/x93-063.

Pubmed: Author and Title

Google Scholar: Author Only Title Only Author and Title

Rugini, E. 1986. "Olive (Olea Eu- Ropaea L.)." In Biotechnology in Agri- Culture and Forestry, Springer, $253-67$.

Pubmed: Author and Title

Google Scholar: Author Only Title Only Author and Title

Ryan, M.G., D. Binkley, and J.H. Fownes. 1997. "Age Related Decline in Forest Productivity: Pattern and Process." Advances in Ecological Research 27: 213-62.

Pubmed: Author and Title

Google Scholar: Author Only Title Only Author and Title

Saze, Hidetoshi, Ortrun Mittelsten Scheid, and Jerzy Paszkowski. 2003. "Maintenance of CpG Methylation Is Essential for Epigenetic Inheritance during Plant Gametogenesis." Nature Genetics. https://doi.org/10.1038/ng1138.

Pubmed: Author and Title

Google Scholar: Author Only Title Only Author and Title

Schermelleh, Lothar, Andrea Haemmer, Fabio Spada, Nicole Rö Sing, Daniela Meilinger, Ulrich Rothbauer, M Cristina Cardoso, and Heinrich Leonhardt. 2007. "Dynamics of Dnmt1 Interaction with the Replication Machinery and Its Role in Postreplicative Maintenance of DNA Methylation." Nucleic Acids Research 35 (13): 4301-12. https://doi.org/10.1093/nar/gkm432.

Pubmed: Author and Title

Google Scholar: Author Only Title Only Author and Title 
Schmitz, Robert J., Matthew D. Schultz, Mark A Urich, Joseph R. Nery, Mattia Pelizzola, Ondrej Libiger, Andrew Alix, et al. 2013.

"Patterns of Population Epigenomic Diversity." Nature. https://doi.org/10.1038/nature11968.

Pubmed: Author and Title

Google Scholar: Author Only Title Only Author and Title

Schneider, Caroline A Wayne S Rasband, and Kevin WEliceiri. 2012. "NIH Image to ImageJ: 25 Years of Image Analysis." Nature Methods 9 (7): 671-75. https://doi.org/10.1038/NMETH.2089.

Pubmed: Author and Title

Google Scholar: Author Only Title Only Author and Title

Slotkin, R Keith, Matthew Vaughn, Filipe Borges, Milos Tanurdzić, Jörg D Becker, José A Feijó, and Robert A Martienssen. 2009. "Epigenetic Reprogramming and Small RNA Silencing of Transposable Elements in Pollen." Cell 136 (3): $461-72$.

https://doi.org/10.1016/j.cell.2008.12.038.

Pubmed: Author and Title

Google Scholar: Author Only Title Only Author and Title

Smyth, G. K., J. Michaud, and H. S. Scott. 2005. "Use of Within-Array Replicate Spots for Assessing Differential Expression in Microarray Experiments." Bioinformatics 21 (9): 2067-75. https://doi.org/10.1093/bioinformatics/bti270.

Pubmed: Author and Title

Google Scholar: Author Only Title Only Author and Title

Song, Jie, Judith Irwin, and Caroline Dean. 2013. "Minireview Remembering the Prolonged Cold of Winter." Current Biology $23: 807-11$. https://doi.org/10.1016/j.cub.2013.07.027.

Pubmed: Author and Title

Google Scholar: Author Only Title Only Author and Title

Suzuki, Miho M, and Adrian Bird. 2008. "DNA Methylation Landscapes: Provocative Insights from Epigenomics." Nature Reviews.

Genetics 9 (6): 465-76. https://doi.org/10.1038/nrg2341.

Pubmed: Author and Title

Google Scholar: Author Only Title Only Author and Title

Telfer, Abby, Krista M. Bollman, and R. Scott Poethig. 1997. "Phase Change and the Regulation of Trichome Distribution in Arabidopsis Thaliana." Development 124: 645-54. https://dev.biologists.org/content/develop/124/3/645.full.pdf.

Pubmed: Author and Title

Google Scholar: Author Only Title Only Author and Title

Untergasser, Andreas, Harm Nijveen, Xiangyu Rao, Ton Bisseling, René Geurts, and Jack AM. Leunissen. 2007. "Primer3Plus, an Enhanced Web Interface to Primer3 Nucleic Acids."' https://doi.org/10.1093/nar/gkm306.

Vandesompele, Jo, Katleen De Preter, Filip Pattyn, Bruce Poppe, Nadine Van Roy, Anne De Paepe, and Frank Speleman. 2002.

"Accurate Normalization of Real-Time Quantitative RT-PCR Data by Geometric Averaging of Multiple Internal Control Genes." Genome Biology 3 (7): RESEARCH0034. https://doi.org/10.1186/gb-2002-3-7-research0034.

Pubmed: Author and Title

Google Scholar: Author Only Title Only Author and Title

Verhoeven, Koen J F, and Veronica Preite. 2014. "Epigenetic Variation in Asexually Reproducing Organisms." Evolution 68 (3): $644-55$. https://doi.org/10.1111/evo.12320.

Pubmed: Author and Title

Google Scholar: Author Only Title Only Author and Title

Visser, T. 1964. "JUVENILE PHASE AND GROWTH OF APPLE AND PEAR SEEDLINGS." Euphytica. Vol. 13.

https://link.springer.com/content/pdf/10.1007\%2FBF00033299.pdf.

Pubmed: Author and Title

Google Scholar: Author Only Title Only Author and Title

Walker, James, Hongbo Gao, Jingyi Zhang, Billy Aldridge, Martin Vickers, James D. Higgins, and Xiaoqi Feng. 2018. "Sexual-LineageSpecific DNAMethylation Regulates Meiosis in Arabidopsis." Nature Genetics 50 (1): 130-37. https://doi.org/10.1038/s41588-017-0008-5.

Pubmed: Author and Title

Google Scholar: Author Only Title Only Author and Title

Wang, Jia-Wei, Mee Yeon Park, Ling-Jian Wang, Yeonjong Koo, Xiao-Ya Chen, Detlef Weigel, and R. Scott Poethig. 2011. "MiRNA Control of Vegetative Phase Change in Trees." Edited by Ronald R. Sederoff. PLoS Genetics 7 (2): e1002012.

https://doi.org/10.1371/journal.pgen.1002012.

Pubmed: Author and Title

Google Scholar: Author Only Title Only Author and Title

Wassenegger, Michael, Sabine Heimes, Leonhard Riedel, and Heinz L. Sänger. 1994. "RNADirected de Novo Methylation of Genomic Sequences in Plants." Cell 76 (3): 567-76. https://doi.org/10.1016/0092-8674(94)90119-8.

Pubmed: Author and Title

Google Scholar: Author Only Title Only Author and Title

Wilschut, Rutger A, Carla Oplaat, L. Basten Snoek, Jan Kirschner, and Koen J. F. Verhoeven. 2016. "Natural Epigenetic Variation Contributes to Heritable Flowering Divergence in a Widespread Asexual Dandelion Lineage." Molecular Ecology 25 (8): $1759-68$. https://doi.org/10.1111/mec.13502. 
Xi, Yuanxin, and Wei Li. 2009. "BSMAP: Whole Genome Bisulfite Sequence MAPping Program" BMC Bioinformatics 10 (1): 232. https://doi.org/10.1186/1471-2105-10-232.

Pubmed: Author and Title

Google Scholar: Author Only Title Only Author and Title

Zhang, Xiaoyu, Junshi Yazaki, Ambika Sundaresan, Shawn Cokus, Simon WL Chan, Huaming Chen, lan R. Henderson, et al. 2006. "Genome-Wide High-Resolution Mapping and Functional Analysis of DNAMethylation in Arabidopsis." Cell 126 (6): $1189-1201$. https://doi.org/10.1016/j.cell.2006.08.003.

Pubmed: Author and Title

Google Scholar: Author Only Title Only Author and Title

Zhang, Xin Zhong, Yong Bo Zhao, Chun Min Li, Dong Mei Chen, Guang Peng Wang, Rui Feng Chang, and Huai Rui Shu. 2007. "Potential Polyphenol Markers of Phase Change in Apple (Malus Domestica)." Journal of Plant Physiology 164 (5): $574-80$. https://doi.org/10.1016/j.jplph.2006.03.011.

Pubmed: Author and Title

Google Scholar: Author Only Title Only Author and Title

Zlberman, Daniel, Mary Gehring, Robert K Tran, Tracy Ballinger, and Steven Henikoff. 2007. "Genome-Wide Analysis of Arabidopsis Thaliana DNA Methylation Uncovers an Interdependence between Methylation and Transcription." Nature Genetics 39 (1): $61-69$. https://doi.org/10.1038/ng1929.

Pubmed: Author and Title

Google Scholar: Author Only Title Only Author and Title

Zimmerman, R.H. 1973. "JUVENILITY AND FLOWERING OF FRUIT TREES." In Acta Horticulturae 34: Symposium on Growth Regulators in Fruit Production, 139-42. Beltsville, Maryland, USA https://doi.org/10.17660/ActaHortic.1973.34.17.

Pubmed: Author and Title

Google Scholar: Author Only Title Only Author and Title 